\title{
UN LOTE DE ARMAS PROCEDENTE DE LA NECRÓPOLIS IBÉRICA DE TORREMORANA (BAENA, CÓRDOBA)*
}

\author{
POR
}

\author{
MANUEL SIERRA MONTESINOS
}

\section{RESUMEN - ABSTRACT}

Este artículo da a conocer una serie de armas de época ibérica procedentes de una necrópolis en Torremorana (Baena, Córdoba). Fueron donadas a los museos museos arqueológicos locales de Baena y Almedinilla, donde se hallan depositadas. Se trata de una falcata, una espada de frontón, soliferrea, puntas de lanza y una manilla de escudo de aletas con una cronología coherente de en torno a muy finales del $\mathrm{s}$. $\mathrm{V}$ o las primeras décadas del s. IV a. C.

This paper presents a group of Iberian Iron Age weapons from a cemetery at Torremorana (Baena, Córdoba). These were donated to the local Archaeological Museums at Baena and Almedinilla, where they are kept. The series consists of a falcata sword, a frontón sword, soliferrea, spearheads and a shield handgrip. All these objects are consistent with a date of circa 420-350 BC.

\section{PALABRAS CLAVE - KEY WORDS}

Cultura Ibérica. Armas. Necrópolis.

Iberian Iron Age Culture. Weapons. Cemetery.

\section{INTRODUCCIÓN}

El presente trabajo tiene por objeto el estudio de una serie de piezas, en concreto armamento, depositadas en los museos arqueológicos de Baena y Almedinilla². Este material, recogido y donado a los citados museos, tras el expolio realizado por unos clandestinos en el

* Este trabajo se inscribe dentro una de las líneas de investigación desarrolladas por el Grupo de Investigación HUM 721 del Plan Andaluz de Investigación, del que es responsable el Prof. D. Pedro J. Lacort Navarro a quien agradecemos sus amables sugerencias.

Del mismo modo, mostramos nuestro agradecimiento al Prof. D. Fernando Quesada Sanz, reconocido especialista en la materia, por sus atinadas observaciones, que, sin duda, enriquecen sustancialmente nuestro trabajo.

2 Queremos manifestar nuestro agradecimiento por la disposición y generosidad mostrada para con nuestro trabajo, a D. Ignacio Muñiz Jaén, director del Museo Histórico Local de Almedinilla, así como a D. Miguel A. Hidalgo Miranda, técnico de la Concejalía de Cultura del Ayuntamiento de Baena, por facilitarnos el acceso a los materiales objeto del presente estudio y aportar las pistas conducentes a esclarecer su procedencia. Igualmente agradecemos a D. Rafael Carmona Ávila, director del Museo Histórico de Priego de Córdoba sus desinteresadas y amables indicaciones sobre la localización del material de nuestro interés. 
yacimiento de Torremorana ${ }^{3}$, nos da pie a realizar algunas reflexiones y propuestas recogidas al final de este artículo.

\section{EL YACIMIENTO}

Torremorana, en el término municipal de Baena (Córdoba) (Figs. 1, 2 y 3), cercano al conocido como «Cerro del Montecillo», con el cual se confunden en ocasiones los lugareños, se encuentra en la Finca Alcalaíta, Cortijo de la Vela localizado en la cartografía 1:10.000 coordenadas UTM $x=387.669, \mathrm{y}=4167.800$, a unos 500 metros al sur del vértice geodésico. Es un yacimiento que se conoce en la bibliografía desde $1970^{4}$.

Se trata de un oppidum de mediana extensión, (Láms. 1,2) unas 5 hectáreas, ocupado al menos desde el periodo Orientalizante hasta época romana (S. I d. C.) en función de los materiales cerámicos que de él se conocen (Murillo et alii, 1989: 160-163). Es, junto a Ucubi (Espejo) y Torreparedones punto dominante de la Campiña cordobesa (Lám. 3). Desde su privilegiada situación de control sobre el río Guadajoz, enlaza visualmente con los grandes oppida de la Campiña como Torreparedones y buena parte de su red de recintos, Cerro Boyero, Cerro de los Molinillos y por la zona al sur del antiguo Salsum, con la red de recintos presidida por Plaza de Armas-Vistillas y el Cerro del Minguillar.(FORTEA, BERNIER, 1970: 33-34; BERNIER et alii, 1981; MURILLO et alii, 1989: 160-163). Torremorana se insertaba en parte de una ruta de época ibérica que comunicaba Obulco con Ipagro hasta Anticaria (BERNIER et alii 1981; MELCHOR, 1986; MURILLO et alii 1989: 169).

Es un yacimiento cuyo continuado expolio está arrojando materiales procedentes de ajuares funerarios muy interesantes (sobretodo $\operatorname{armas}^{5}$ y cerámica ${ }^{6}$ ), dentro de una zona que está contribuyendo a clarificar cuestiones de distribución y adscripción del armamento ibérico ${ }^{7}$.

\section{ESTUDIO DE LOS MATERIALES}

El estudio de los materiales que presentamos a continuación parte con un cierto handicap: la imposibilidad por falta de medios y permisos de someter las piezas a un necesario, en su mayoría, proceso de restauración, limpieza y/o análisis radiológico, que, a buen seguro, arrojaría una serie de datos tecnológicos que sólo en contados casos se pueden detectar a simple vista ${ }^{8}$. Confiamos en poderlo realizar en un futuro próximo. No obstante no renun-

3 Las piezas de los dos museos proceden de donaciones de un mismo particular, que desea mantenerse en el anonimato, quien nos indicó que tras el expolio de diversos clandestinos en el yacimiento, « recolectó « las piezas objeto de nuestro estudio y las donó a los citados museos. Así pues, las circunstancias del hallazgo podrían poner en cuarentena la rotundidad de la afirmación implícita en el título de este trabajo,que, de cualquier modo y con las debidas reservas mantenemos, siendo signifi -cativa en este sentido la reciente aparición en este lugar de otras piezas de armamento ibérico, elementos constituyentes igualmente de ajuar funerario (QUESADA, 2001:73).

4 FORTEA, BERNIER, 1970; BERNIER et alii, 1981; AlMAGRO-GORBEA, 1986; MURILlo et alii, 1989; MoRET; 1996.

5 QuesadA, 2001; Sierra, 2001; SiERra, PEREZ, (e. p.).

6 Está en fase de estudio por nuestra parte un conjunto de piezas cerámicas procedentes del yacimiento de Torremorana depositadas en el Museo Histórico Local de Almedinilla, así como la confirmación de otras depositadas en el Museo Arqueológico de Baena.

7 Torremorana destaca por su situación al oeste de la línea imaginaria que traza F. Quesada en la dispersión del armamento ibérico, (QUESADA, 2001) muy cercana a la zona fronteriza de los dos ámbitos culturales en que suele dividirse la cuenca del Guadalquivir (F. PEREIRA, 1988 y 1989) y por sus materiales, que avanzamos, netamente ibéricos (QUESADA, 1999).

8 Destacan en este sentido los análisis de los materiales procedentes de las excavaciones de la necrópolis de La Serreta ( Miro, ReIG, 1997) (PrATS, Rovira, Miro, 1996) y de la necrópolis de la Hoya (Alonso, CERDAN, FILlOY, 1999).Esclarecedora es la recensión de F. Quesada a esta última obra (QUESADA, 2000) que recoge ésta y otra bibliografía puntera en este tipo de análisis. 


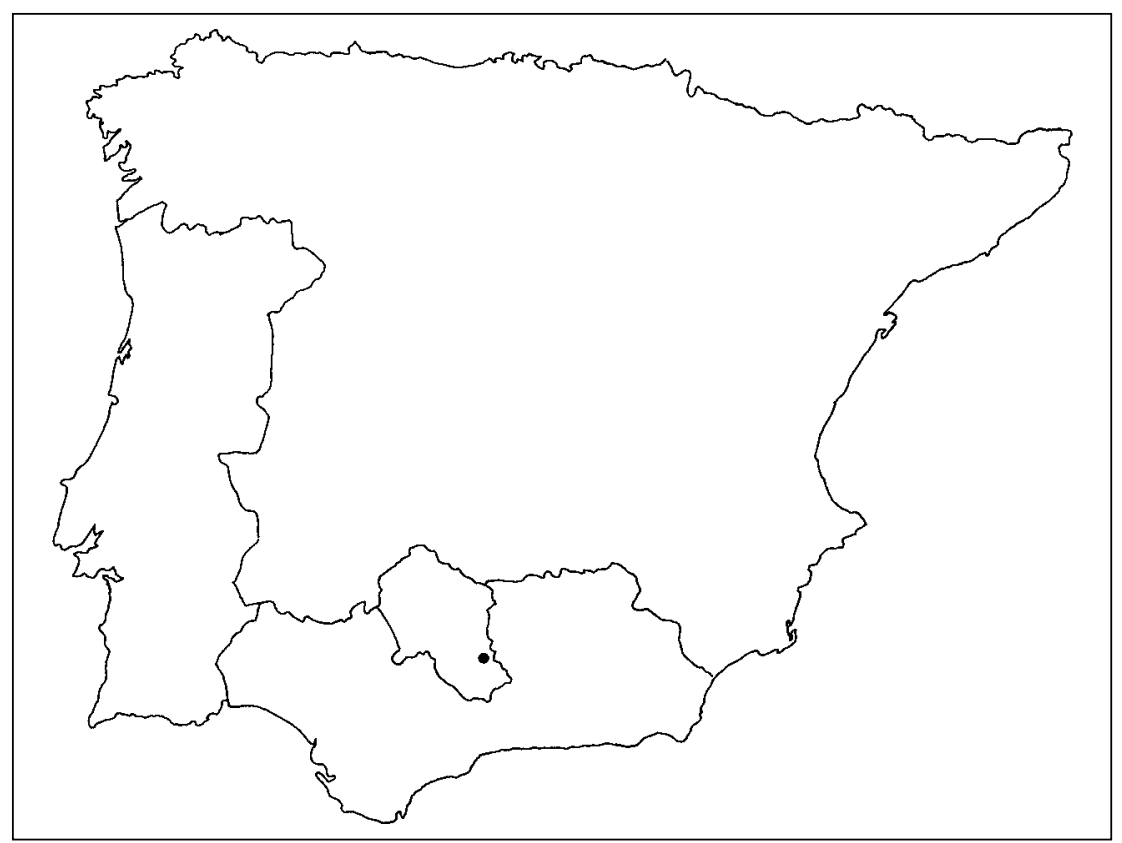

Fig. 1. Situación del yacimiento en el entorno provincial, regional y nacional.

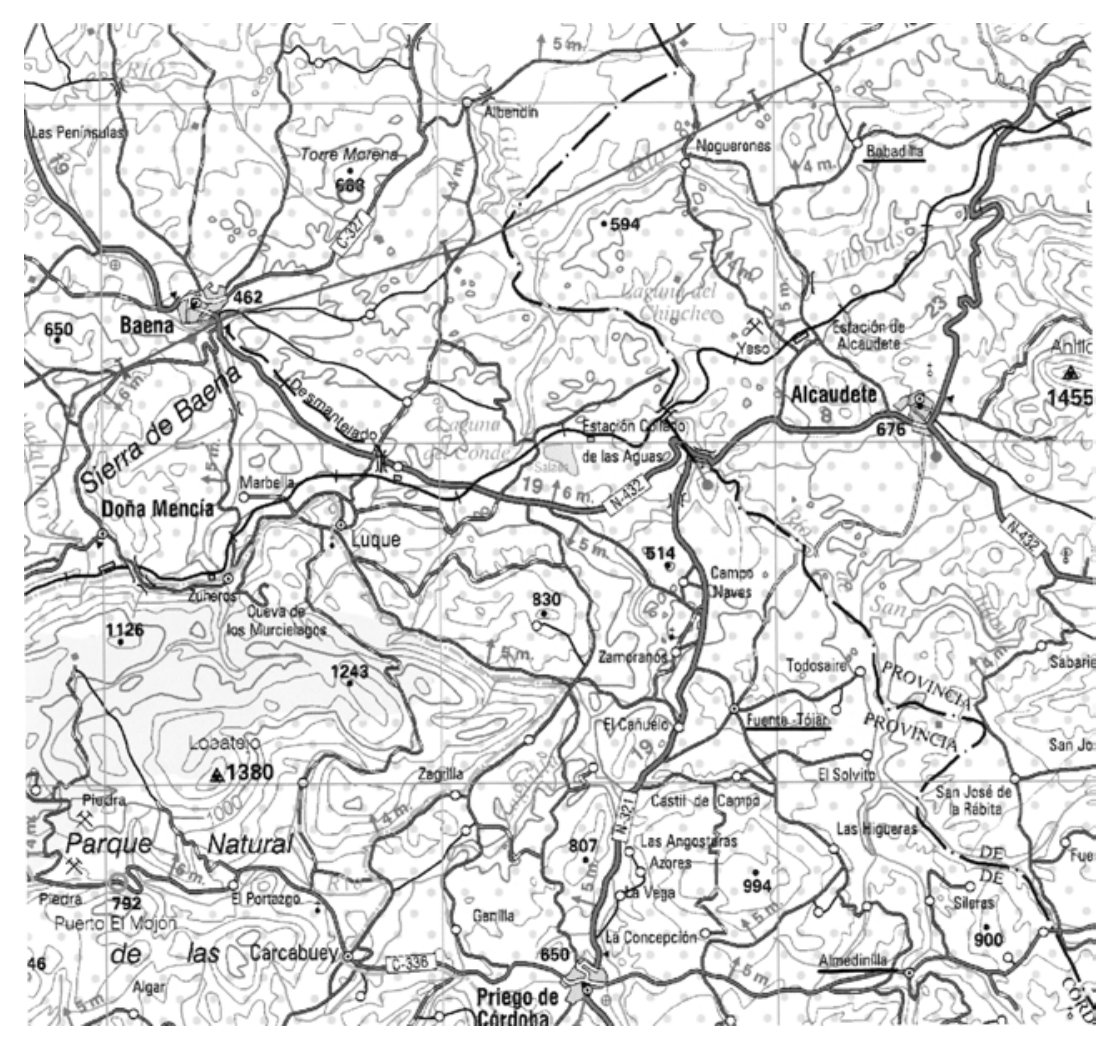

Fig. 2. Situación de Torremorana en relación a las necrópolis ibéricas de la Bobadilla, Fuente Tojar, Almedinilla y las mas próximas de su entorno. 


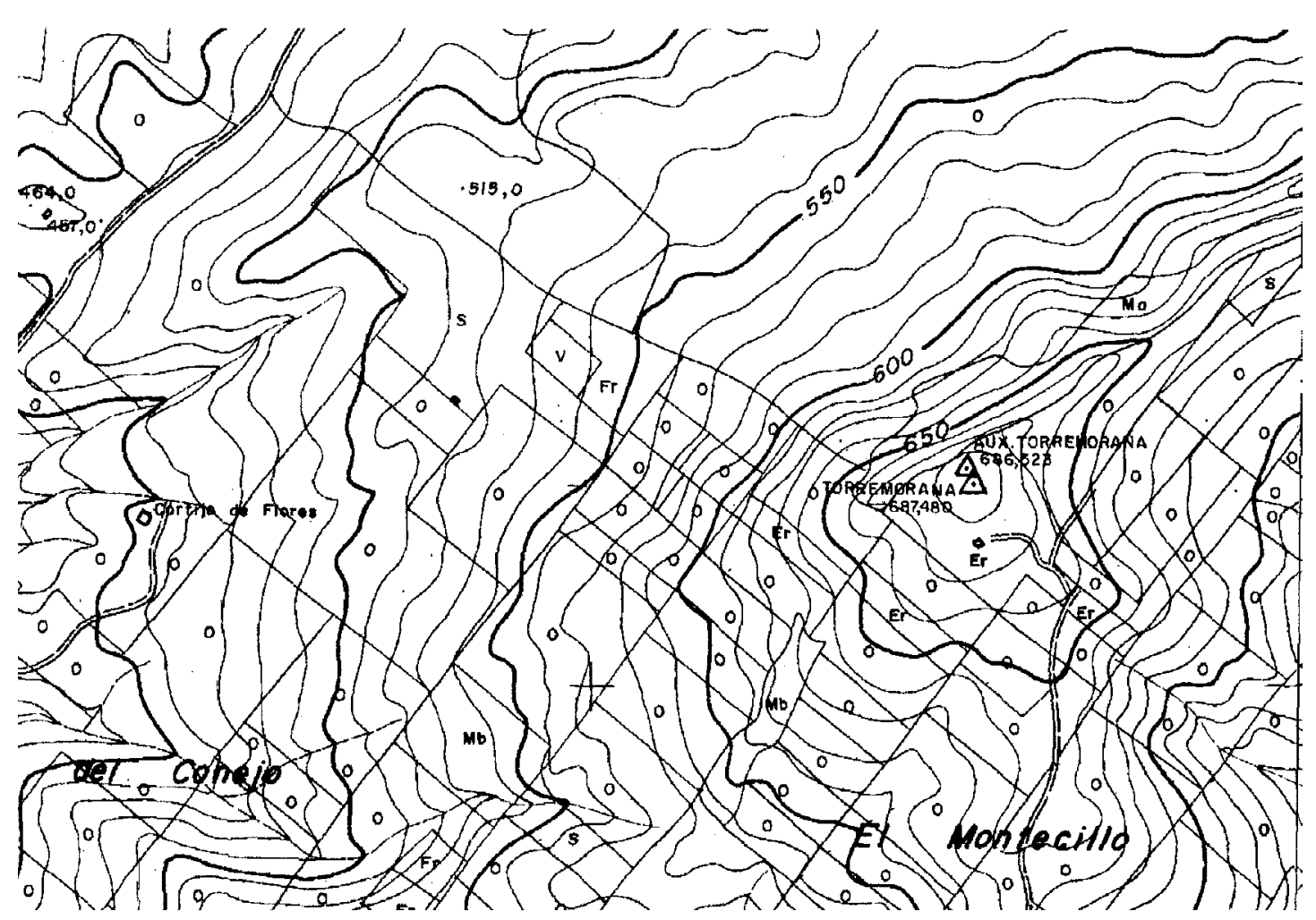

Fig. 3. Torremorana $-E=1: 10.000$.

ciamos a exponer opiniones resultado de la observación del material, y sobretodo a su análisis tipológico, que puedan aportar datos referidos a su cronología, dispersión, paralelos, y funcionalidad siguiendo los más modernos y recientes estudios sobre el tema ${ }^{9}$.

\section{FalCATA. (Museo Arqueológico de Baena. Número de registro 98/9/8) (Láms. 4, 5) (Fig. 4).}

Se trata de una pieza de hierro, de la que se conserva la hoja y aproximadamente un tercio de la empuñadura, faltándole el resto y las cachas, de manera que no es posible determinar si se trataba de una pieza con cabeza de ave o de caballo así como si existía o no guarda lateral, de cadenilla o maciza. El ejemplar presenta tal estado de oxidación con adherencias terrosas, que de la manipulación para su estudio se desprendieron numerosas láminas del óxido superficial, aunque conserva el núcleo metálico muy degradado. Como las restantes piezas del Museo de Baena, necesita una urgente intervención de limpieza y restauración.

La hoja está ligeramente ondulada en S, presenta mellas en el filo, sobre todo en la base y en el filo dorsal, que no creemos intencionado sino producto del avanzado estado de corrosión de la pieza. Por este motivo es difícil seguir el trazo de las acanaladuras que presenta. A simple vista podría coincidir con el tipo 0 de Quesada en relación a la disposición de las acanaladuras (Quesada, 1997: 94) por la misma que parece advertirse en la base de la hoja hasta el último tercio de ésta.

9 La obra básica, referente obligado a la hora de abordar cualquier estudio sobre armamento prerromano en la Península Ibérica, es QUESADA, 1997. 


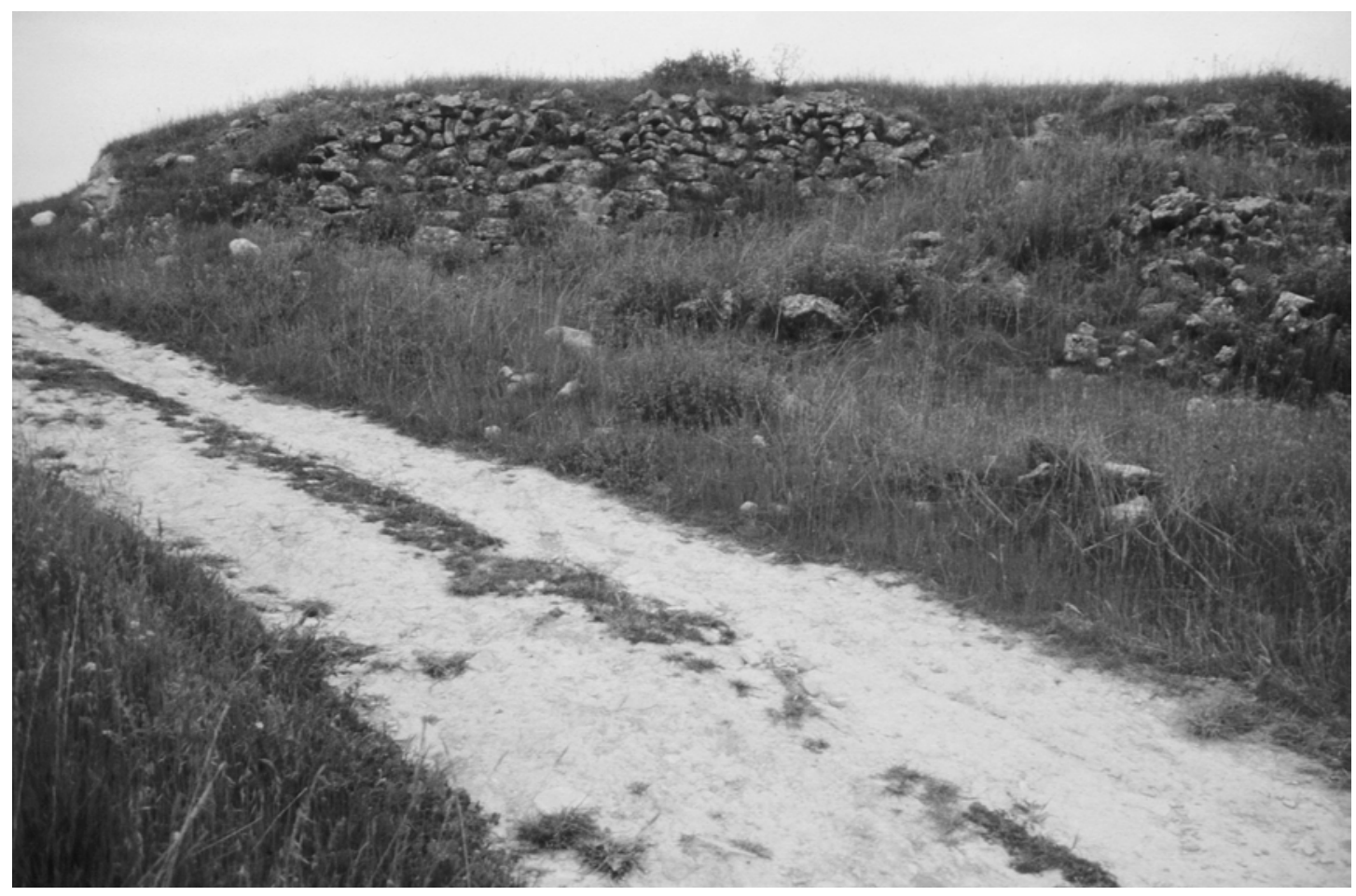

Lam. 1. Torremorana. Detalle de paramento ciclópeo.

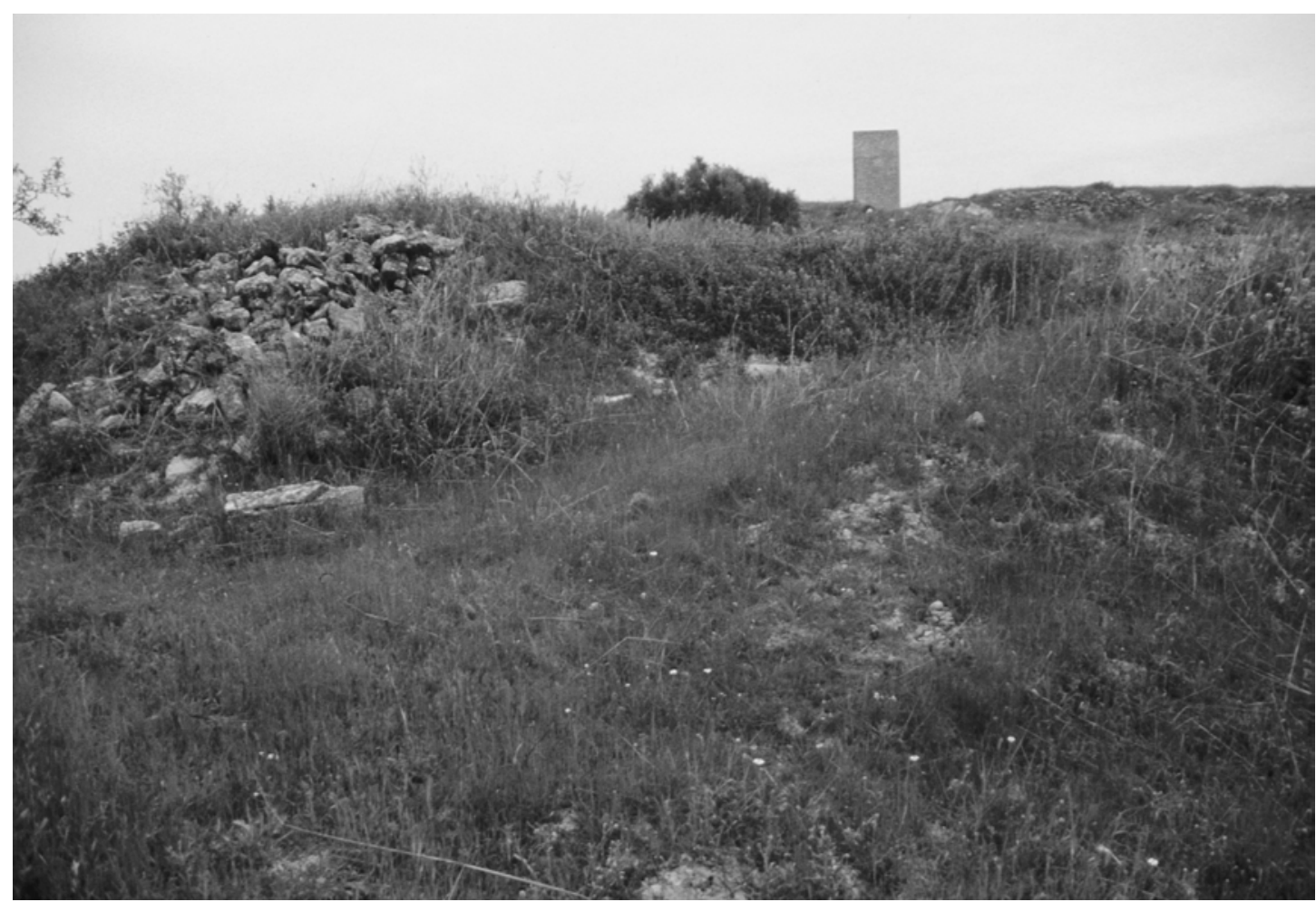

Lam. 2. Yacimiento de Torremorana. Al fondo torre medieval. 


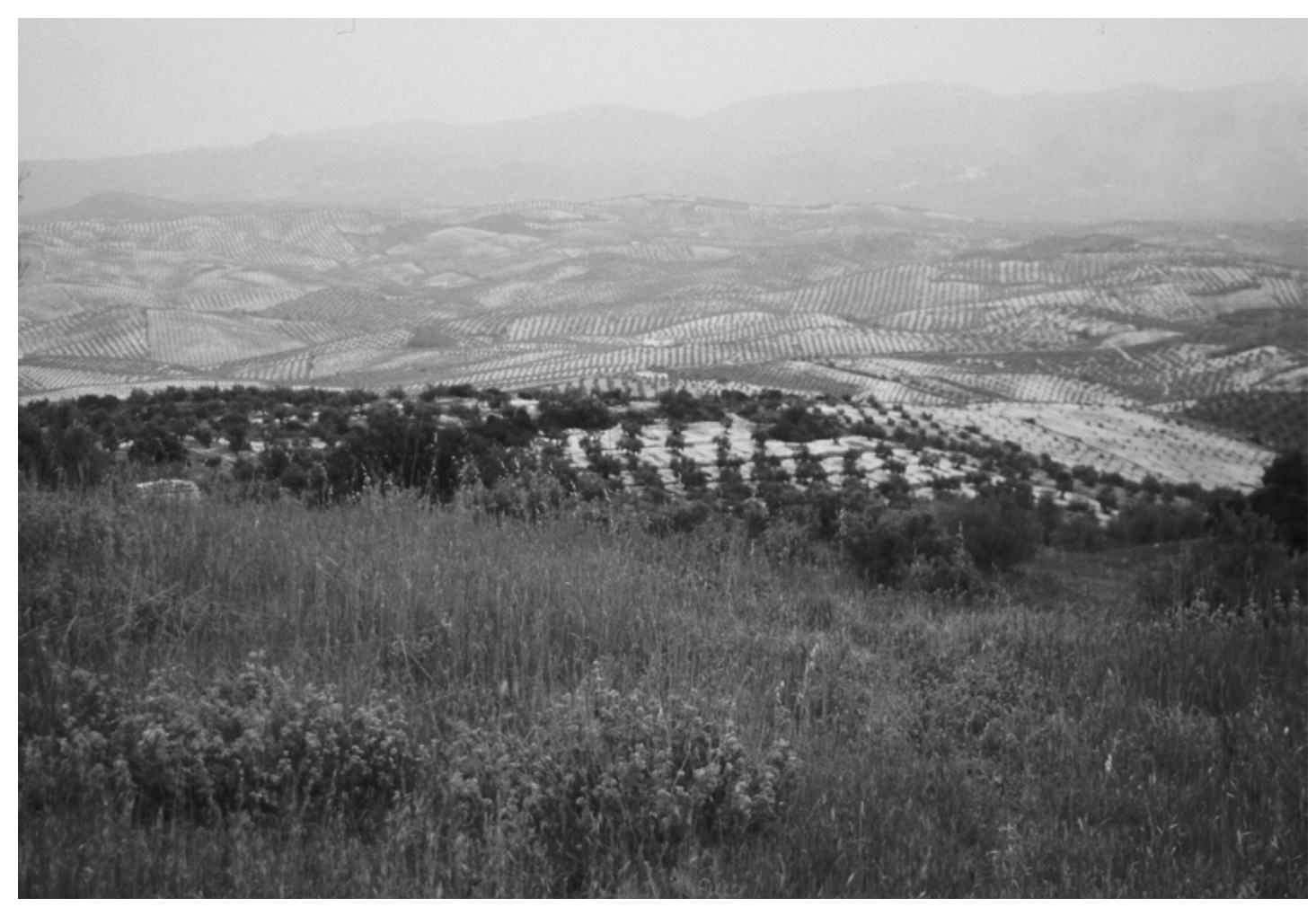

Lam. 3. Vista sobre el valle del río Guadajoz desde el yacimiento.

En la empuñadura se aprecia un remache redondeado para sujeción de las cachas de madera, hueso u otro material orgánico que no se ha conservado.

La guarda basal se aproxima a la del tipo E de E. Cuadrado (CUADRADO 1989: 18-20). Las dimensiones de la falcata son las siguientes ${ }^{10}$ :

- Longitud máxima conservada: 50`6 cm. (creemos que sobre 56-57 la longitud total)

- Longitud de la hoja: $46^{\prime} 6 \mathrm{~cm}$.

- Longitud del filo dorsal: $28 \mathrm{~cm}$.

- Anchura basal: 6’05 cm.

- Anchura máxima de la hoja: 5'5 cm.

- Anchura mínima de la hoja: 2'9 cm.

- Angulo axial: $79^{\circ}$.

- Grosor máximo de la hoja: 0`75 cm.

- Distancia entre el extremo de la punta y la acanaladura del arma: $21 \mathrm{~cm}$.

Creemos que casi llegaría al valor medio de la falcatas estudiadas hasta ahora. F. QUESADA estima en 60'5 cm de longitud media total y $48^{\prime} 9 \mathrm{~cm}$ de media global de la hoja que está en consonancia con los aproximadamente $56-57 \mathrm{~cm}$ de longitud total que proponemos y los $46^{\prime} 6 \mathrm{~cm}$ de longitud de la hoja, y si cabe más cercano a los $45^{\prime} 9 \mathrm{~cm}$ de media para las hojas de falcatas andaluzas (QUESADA 1997:85). No presenta decoración al menos tras un examen visual.

10 Seguimos los criterios de publicación de una falcata recogidos en QUESADA, 1997: 84. 


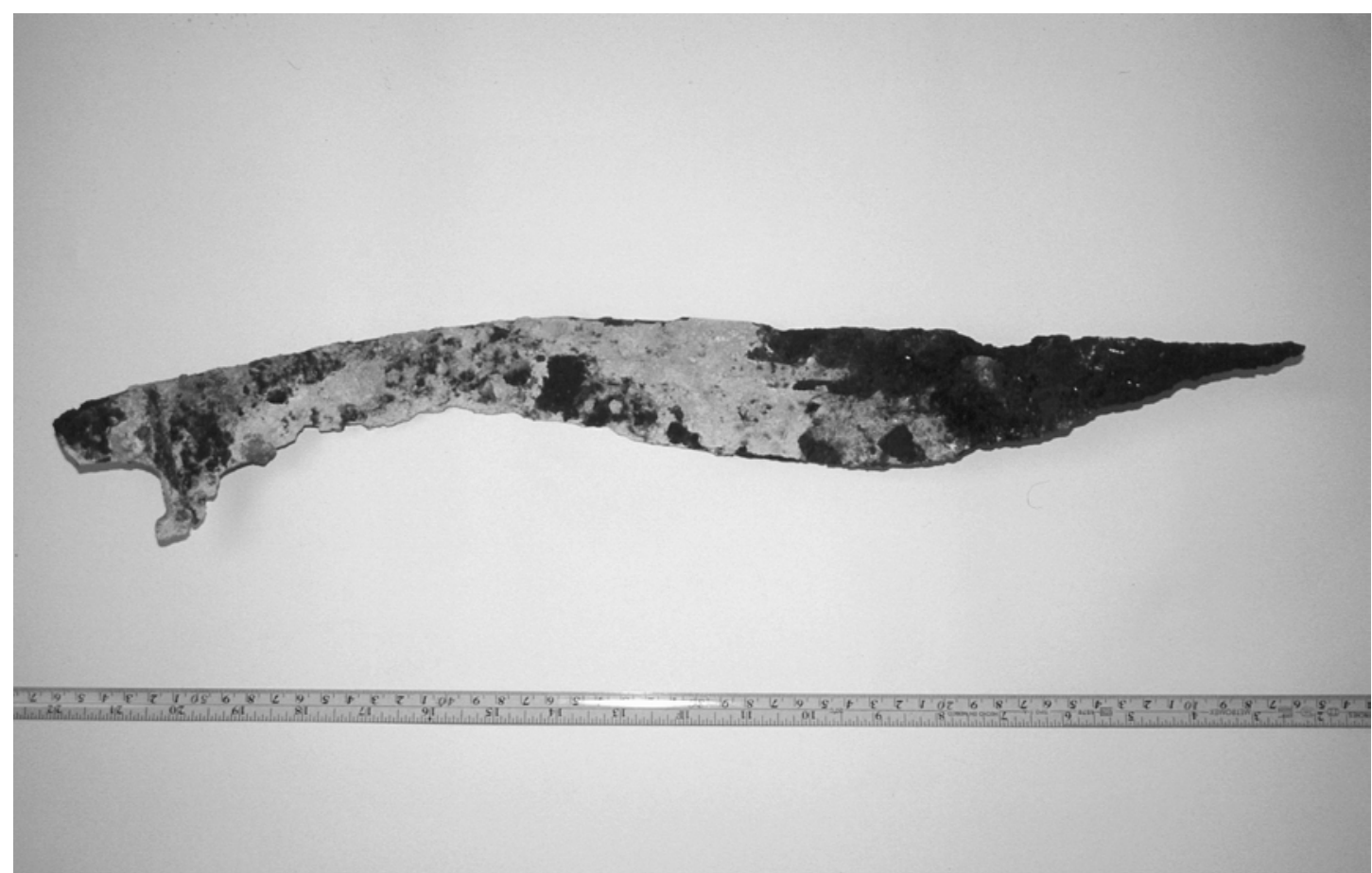

Lam. 4. Falcata. Museo Arqueológico de Baena.

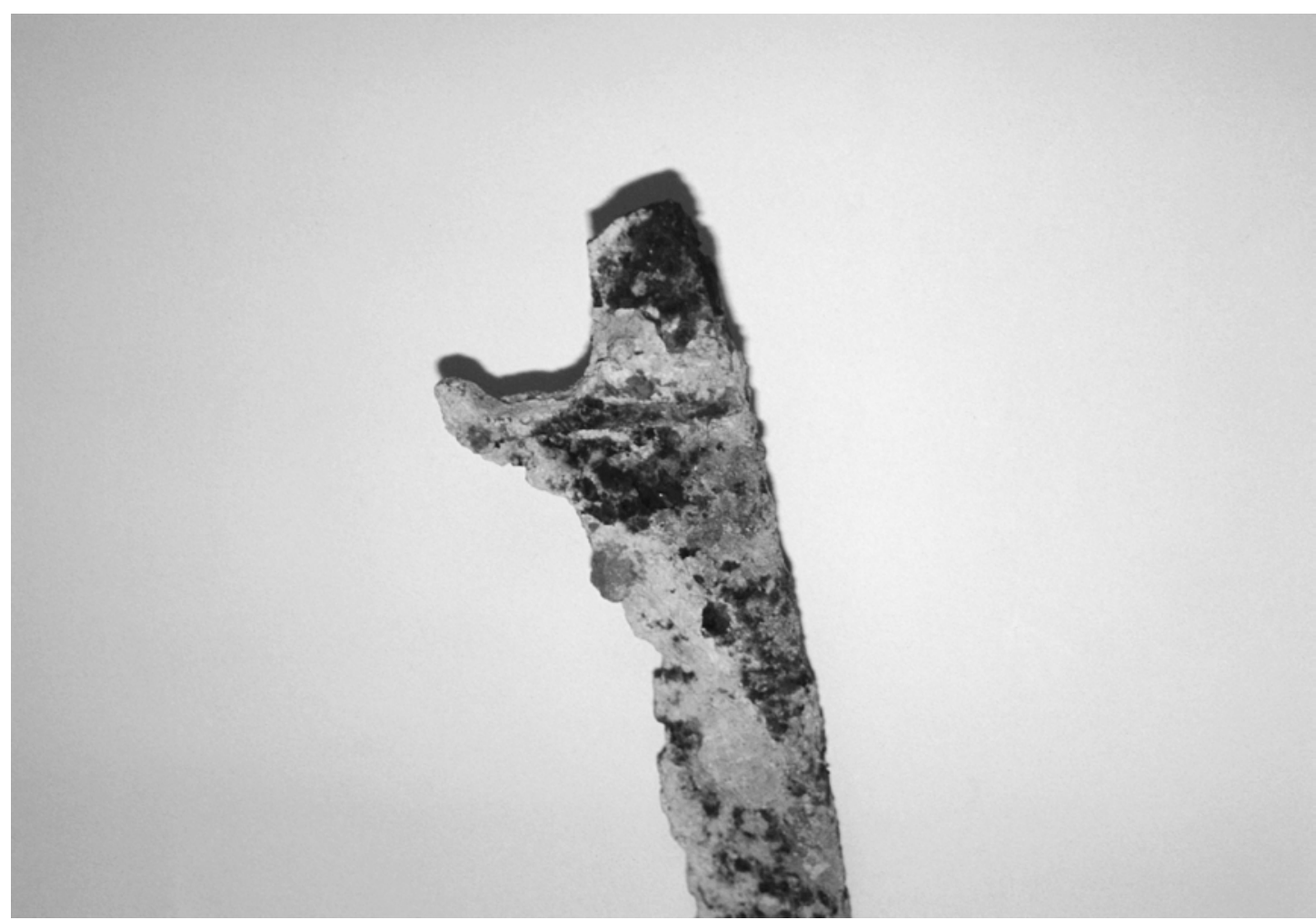

Lam. 5. Detalle falcata anterior. Base de la hoja, guarda y restos de la empuñadura con pasadores. 


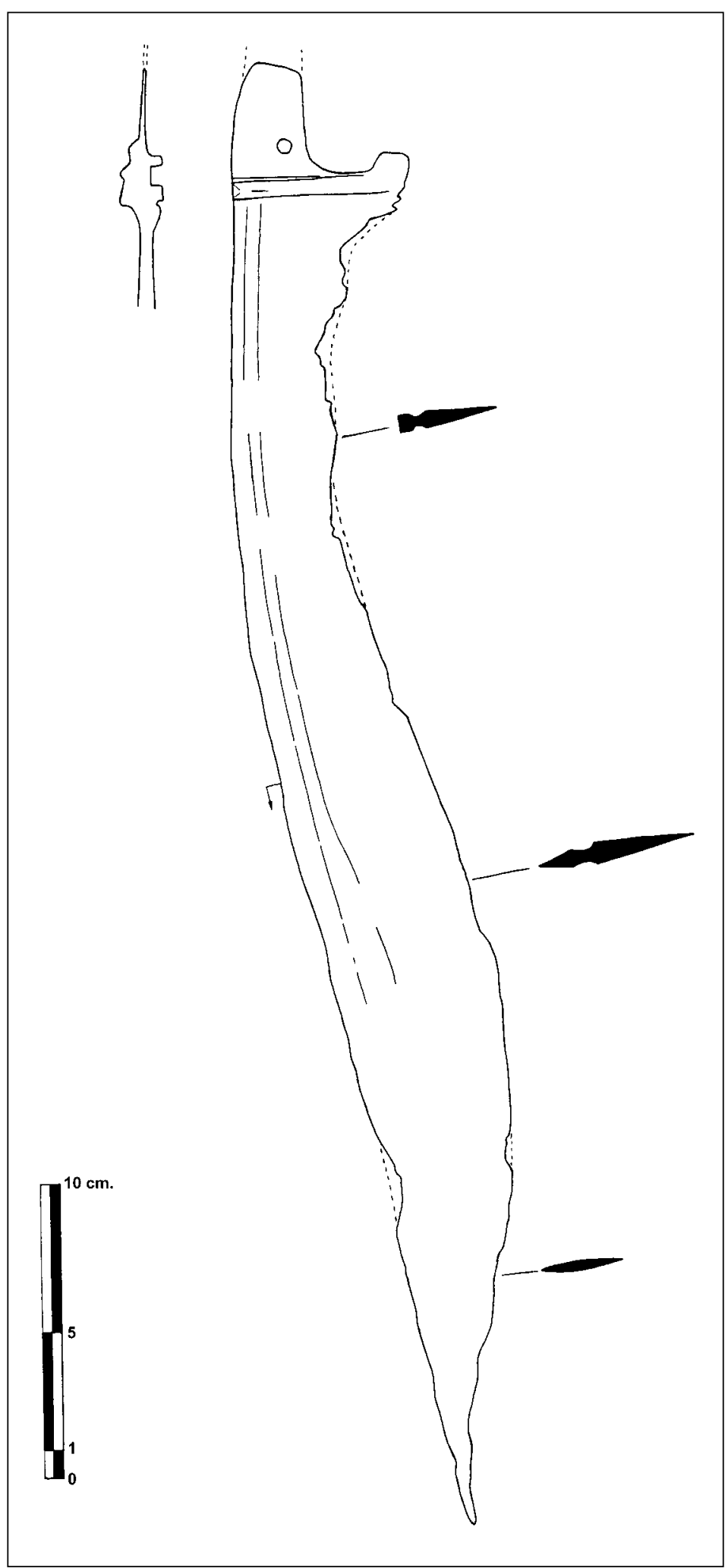

Fig. 4. Falcata.Museo Arqueologico de Baena. 
En cuanto a su encuadre cronológico, debido a las circunstancias del hallazgo no podemos decir mucho. Por paralelos del tipo de guarda basal sistematizadas para el yacimiento de El Cigarralejo por E. Cuadrado tendríamos fechas a todo lo largo del siglo IV a. C. (CUADRADO 1989,18-20) que no deja de ser un mero apunte, sin poder precisar más.

2. ESPADA DE FRONTÓN, RESTOS DEL ARMAZÓN METÁLICO DE LA VAINA. (Museo Histórico de Almedinilla. Número de registro, 2002/15/2) (Lám. 6, 7, 8 ) (Figs. 5, 6).

La pieza es identificable como espada de frontón por la anchura y robustez de su hoja, lengüeta aplanada de espiga, de forma romboidal o losángica y forma ligeramente pistiliforme que desgraciadamente no conserva la guarda, ni las cachas de madera, marfil u otro material perecedero y el característico pomo de variada estructura de forma semicircular (QUESADA, 1997: 183), características estas últimas imprescindibles para su correcta ubicación tipológica. Por estas razones y pese a la solidez de la hoja, ligeramente oxidada en la punta y lengüeta, aunque con algún afloramiento de orín, su estado de conservación lo consideramos como regular. Sus medidas son:

- Longitud máxima conservada (sin el fragmento perdido de la empuñadura) $41^{\prime} 5 \mathrm{~cm}$.

- Longitud de la hoja: $34^{\prime} 05 \mathrm{~cm}$.

- Longitud de la empuñadura (conservada): $8 \mathrm{~cm}$. con $1 \mathrm{~cm}$ aproximadamente para alojar la guarda que no se conserva.

- Anchura máxima de la hoja: 5’5 cm.

- Anchura máxima de la empuñadura: $1^{\prime} 9 \mathrm{~cm}$. Se distinguen dos remaches en la lengüeta para sujeción de las cachas.

La sección de la hoja(Fig. 5) adopta una forma de cuatro mesas definidas por un nervio central redondeado. A ambos lados de dicho nervio existe una ancha acanaladura de base plana que estaría surcada por finas estrías casi perdidas. Se observan en la hoja dos grupos de estrías concéntricas que siguen la línea de la hoja y se unen su tercio inferior. En líneas generales estas medidas muestran un ejemplar algo menor que la media, tanto en longitud total como de la hoja(a pesar de faltarle la parte superior de la empuñadura) y también más esbelta que la media (QUESADA 1997: 184).

Aunque con numerosas manchas de corrosión superficial, en algunas zonas puede apreciarse debajo de las incrustaciones terrosas la superficie original de un tono negruzcoazulado intenso que probablemente se deba a una oxidación intencional a magnetita (QUESADA, 2000: 314-317; PEREZ DAZA Y QUESADA, 2001: 108).

Por la forma de la hoja ligeramente pistiliforme y no demasiado ancha, quizás podríamos encuadrarla en el tipo III, de la clasificación de Quesada (QUESADA, 1997: 187).

De la cronología poco se puede decir al carecer también de los elementos más característicos para identificarla tipológicamente y establecer paralelos. Son armas antiguas que aparecen en el S. VI a.C. en la panoplia ibérica para ser sustituidas rápidamente por la falcata en la zona del Sureste-Alta Andalucía a finales del siglo V a. C.- comienzos del siglo IV a. C. (QUESADA, 1997: 178-183).

Acompañan a la espada dos pequeñas piezas pertenecientes sin duda al armazón metálico de la vaina, que según la persona que las halló se encontraban junto a la espada. Se trata de dos fragmentos, el primero de ellos de unos $4^{\prime} 1 \mathrm{~cm}$. termina en un taladro por el que pasa una anilla de $2 ` 2 \mathrm{~cm}$ de diámetro que servia para sustentar una correa dentro del sistema de suspensión del arma. La tira de hierro tiene forma convexa y pensamos que podría alojar un pequeño cuchillo en la vaina de la espada como sucede en ejemplos de vainas de espadas de este tipo u 
otras de falcatas, como el ejemplo de la espada de frontón de Alpanseque (SCHÜLE, 1969: Taf. 27). El otro fragmento pertenece a la contera de la vaina, es un remate en forma de disco, mide $3^{\prime} 3$ por $2^{\prime} 5 \mathrm{~cm}$. y $1^{\prime} 4 \mathrm{~cm}$ de grosor une las cuatro tiras de hierro en sentido vertical de que constaría el armazón metálico de la vaina. En la concavidad interior encaja de manera perfecta con la punta de la espada. Algunos de estos remates estaban decorados con damasquinado, como por ejemplo la contera hallada en Alcacer-do-Sal (SCHÜLE, 1969: Taf. 96-3) o la de la espada de la zona III de la necrópolis de la Osera (SCHÜLE, 1969: Taf. 121-1). Pero en el caso de nuestro ejemplo la corrosión impide decirnos si fue decorada o no.

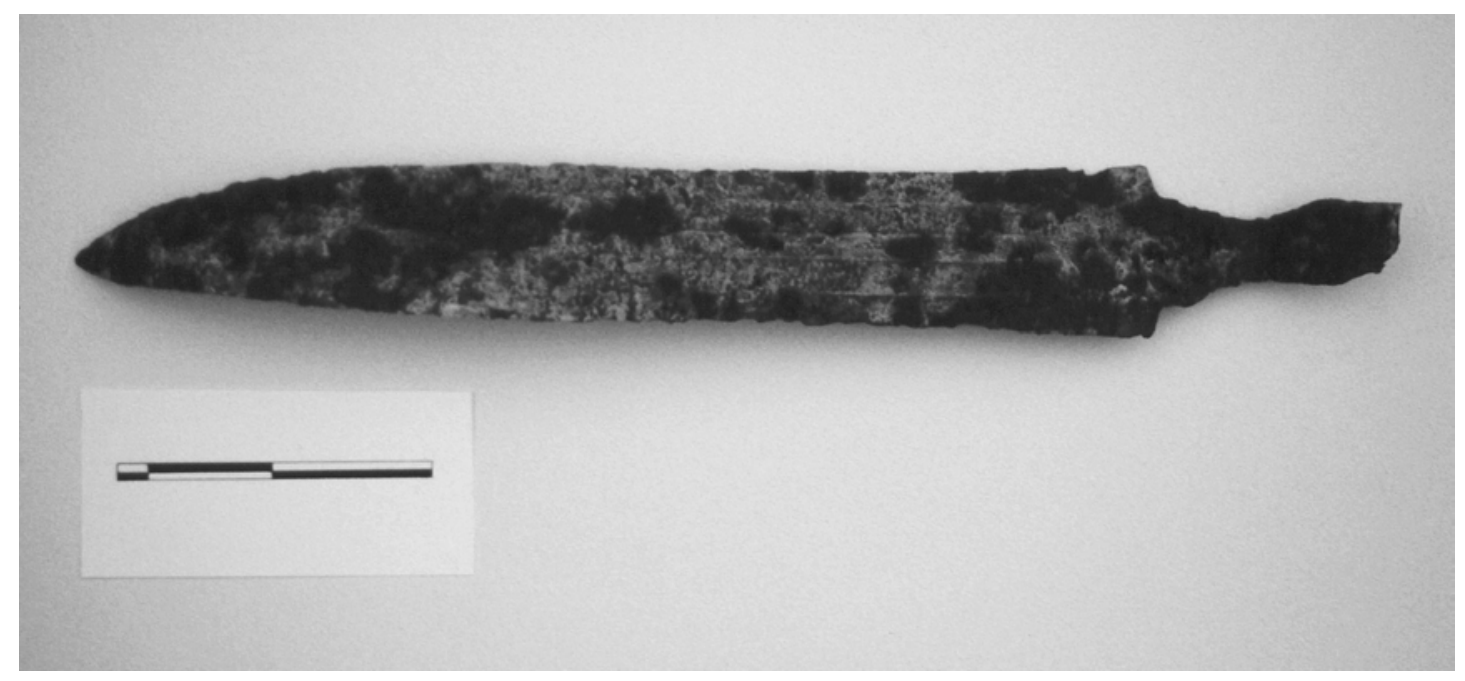

Lam. 6. Espada de frontón. Museo histórico local de almedinilla.

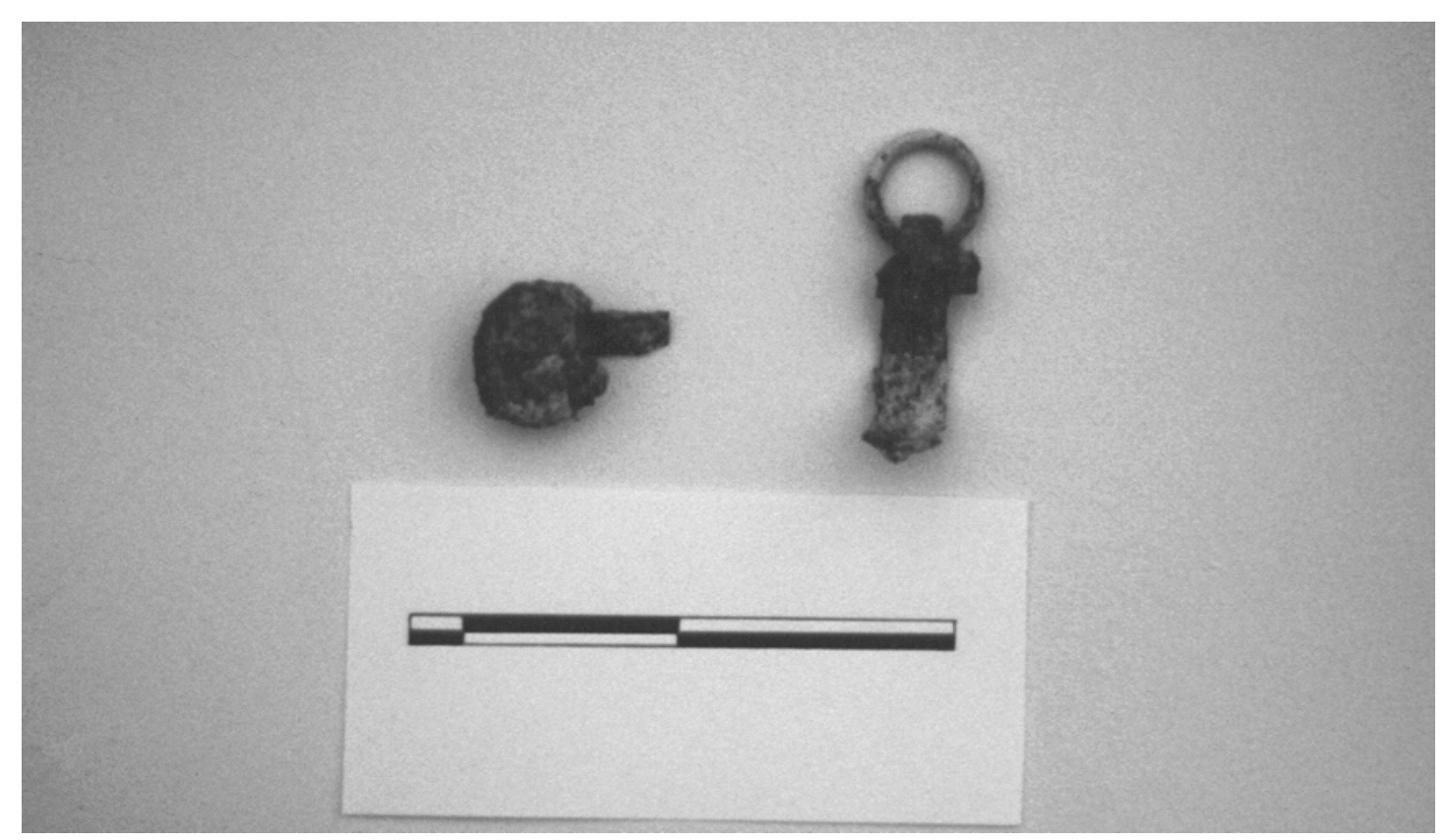

Lam. 7. Restos del armazón de la vaina de la misma espada. 


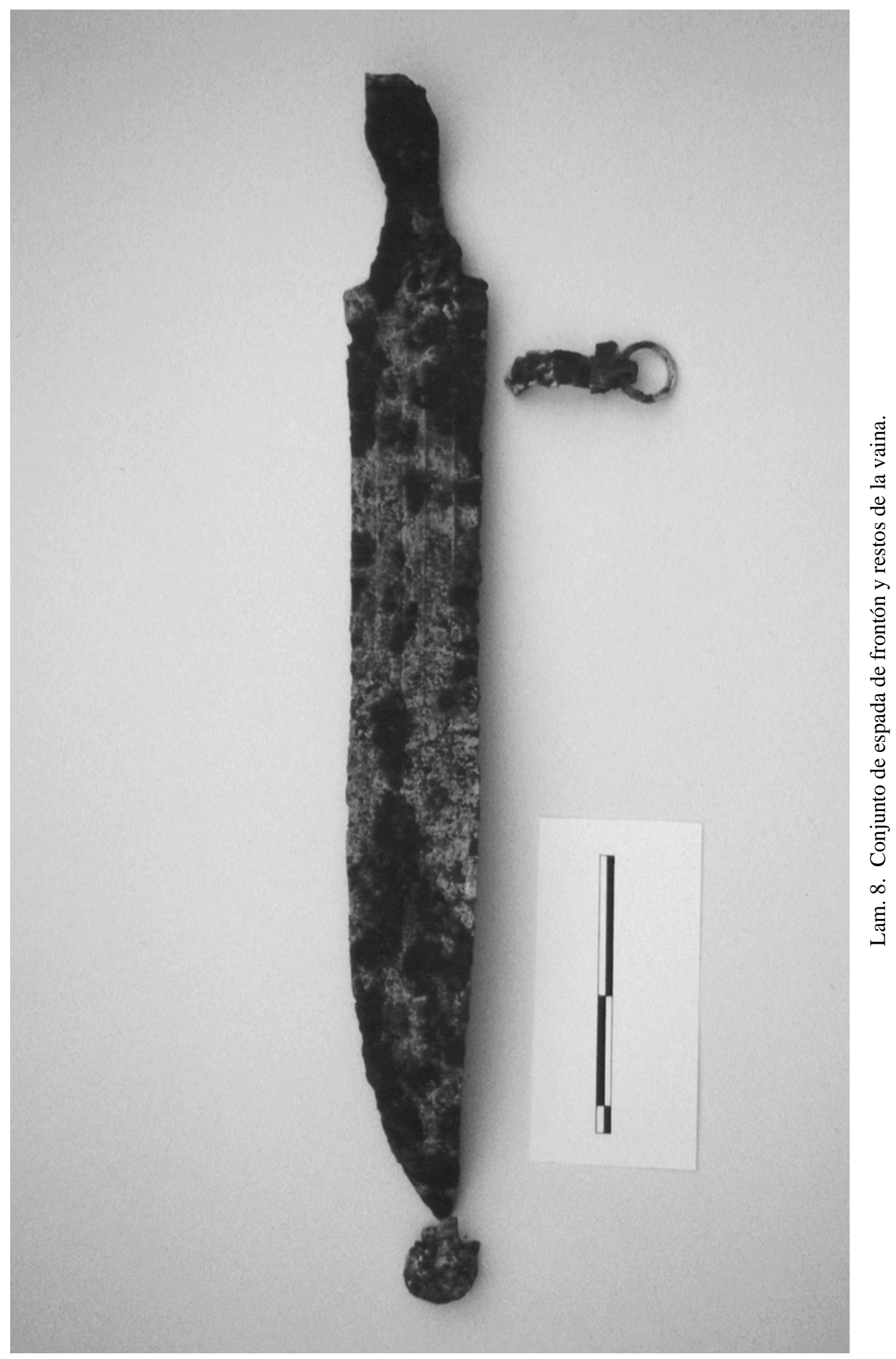



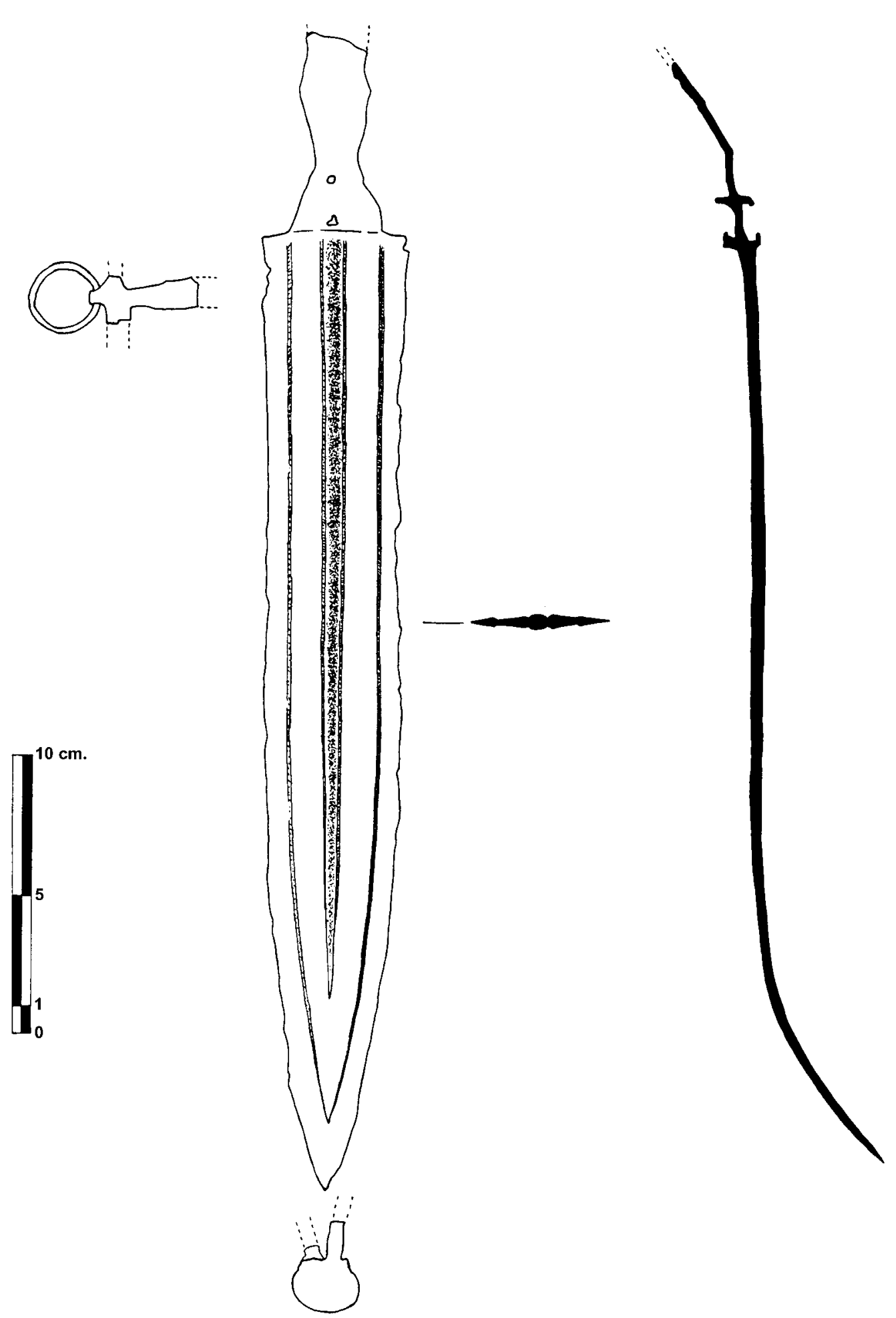

Fig. 5. Espada de frontón. museo histórico local de almedinilla. 


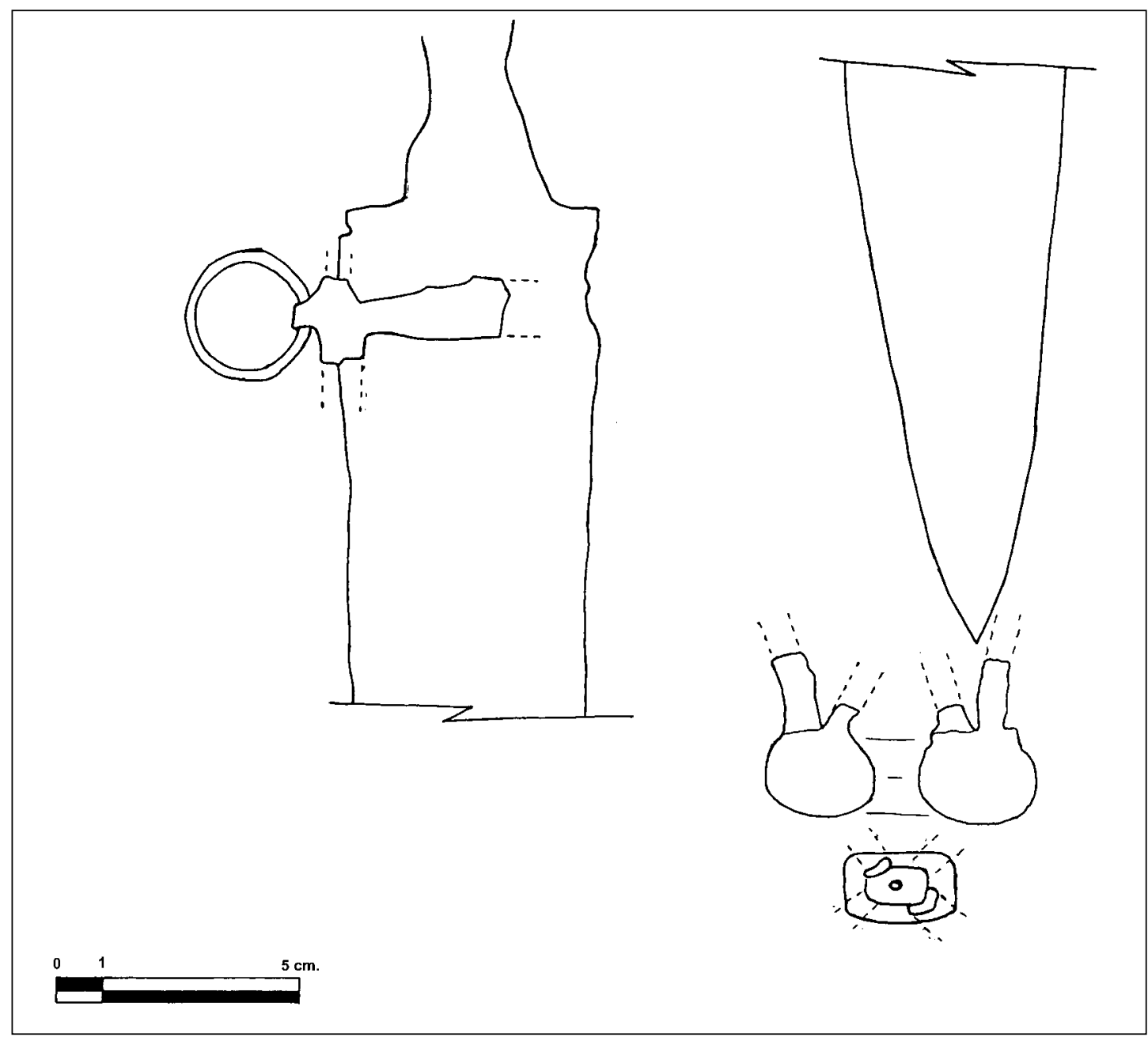

Fig. 6. Fragmentos de la vaina metálica de la espada anterior.

\section{MOHARRAS DE LANZA.}

a) Museo Arqueológico de Baena. Número de registro 98/9/5 (Lám. 9) (Fig. 7). Se trata de la punta mas larga del conjunto, con sus $50 \mathrm{~cm}$ de longitud total, muy esbelta y estrecha, cuya anchura máxima se alcanza en el primer tercio de la hoja (casi en el primer cuarto) y disminuye paulatinamente hasta la punta. Buena conservación a pesar del óxido superficial con incrustaciones terrosas y algunas mellas en sus filos. Presenta un gran nervio de sección redondeada que se pierde e identifica con la punta en su extremo final, así como anillo de fijación y orificio del pasador. No se aprecian restos del capuchón interior o soldadura de cobre en el interior del cubo, ni ranura longitudinal sin sutura (QUESADA, 1997: 345; MIRO, REIG, 1997). Este presenta forma cónica hasta unos $2 \mathrm{~cm}$ del arranque de los filos en el que presenta sección cuadrada. Sus dimensiones son:

- Longitud máxima: 505 cm.

- Longitud de la hoja: $39 \mathrm{~cm}$.

- Anchura máxima de la hoja: 2`7 cm. 


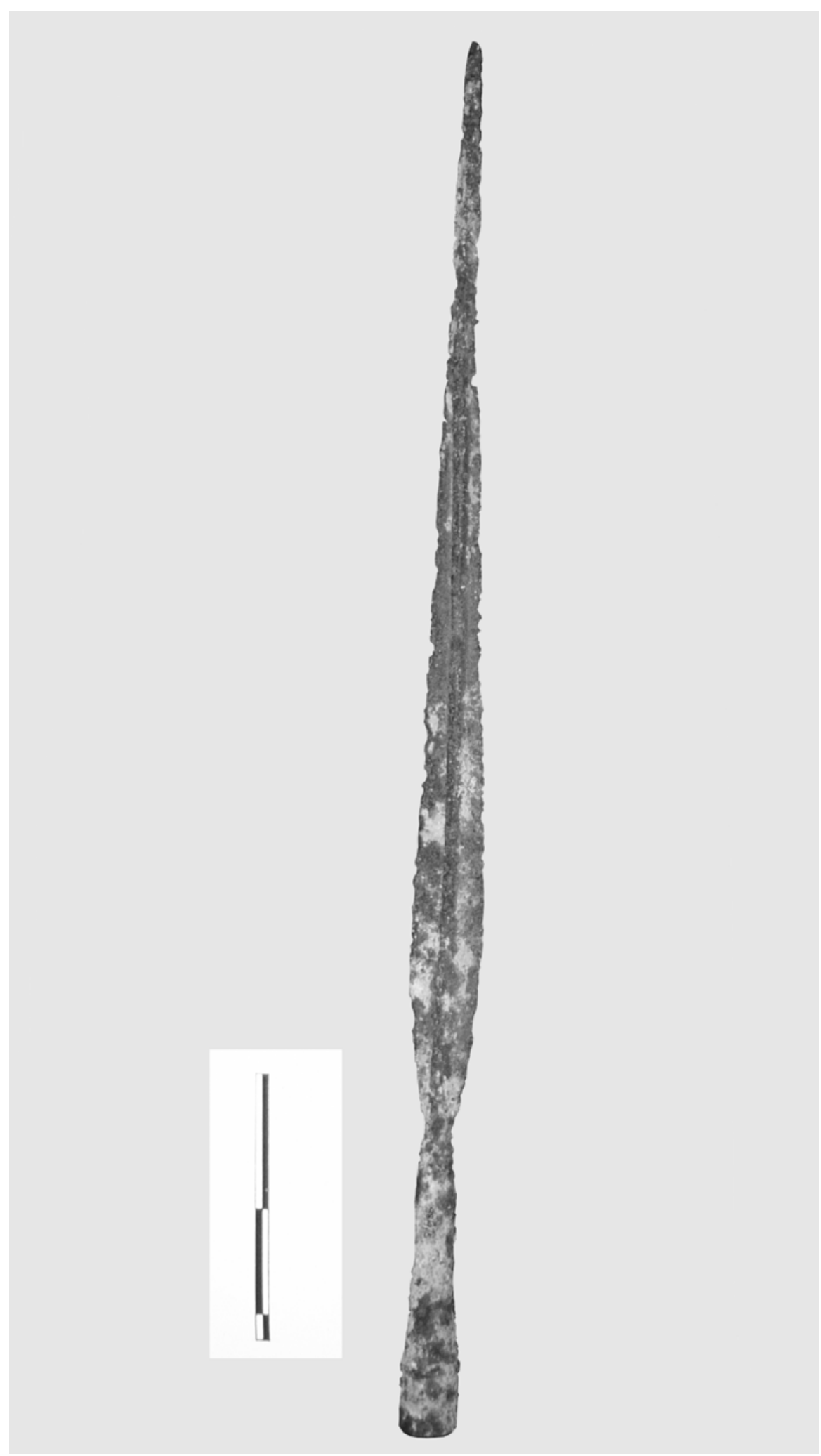

Lam. 9. Moharra de lanza de grandes dimensiones. Museo Arqueológico de Baena. 


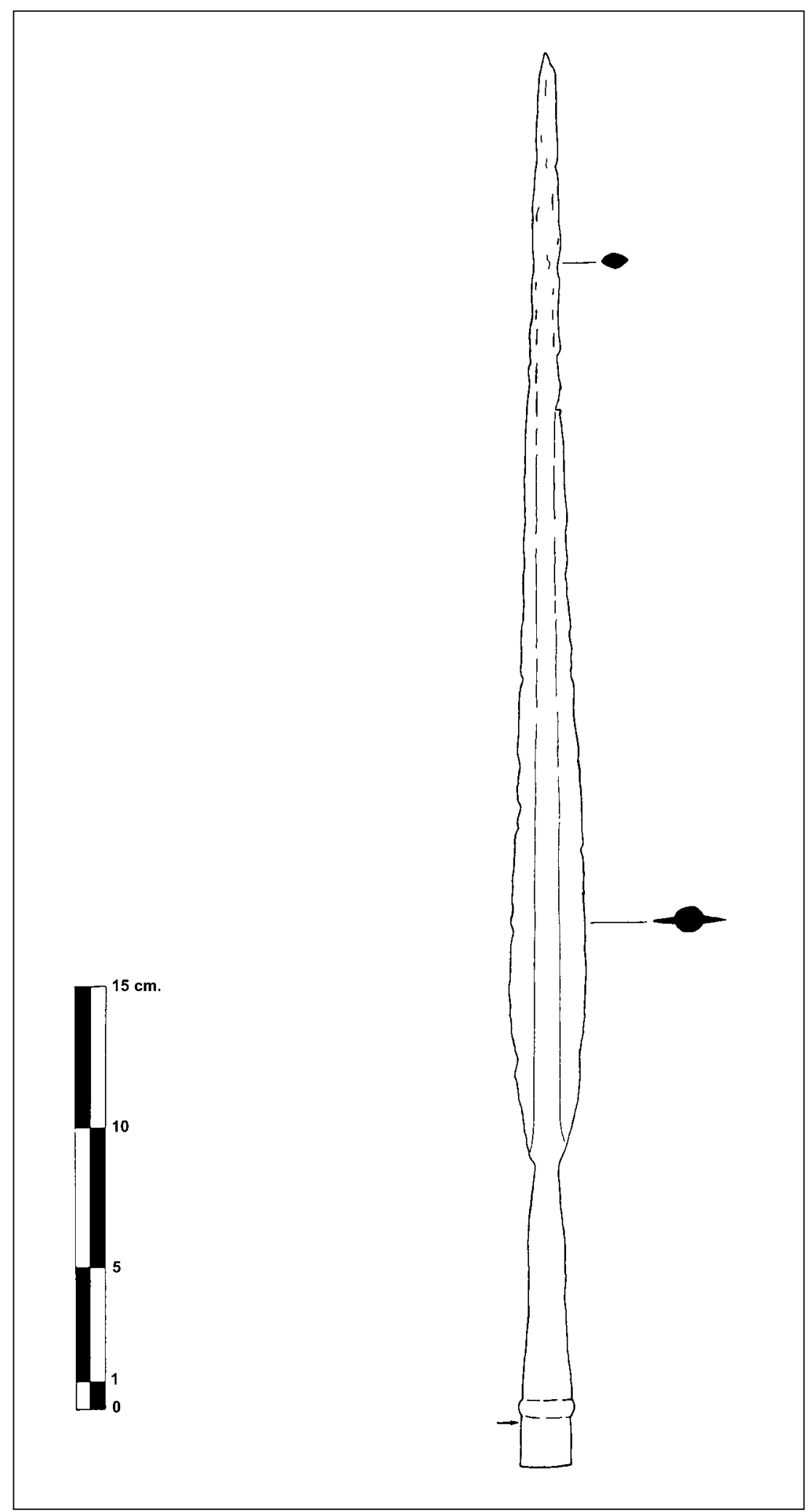

Fig. 7. Moharra de lanza. Museo Arqueológico de Baena. 
- Longitud del cubo: $11^{\prime} 5 \mathrm{~cm}$.

- Diámetro del cubo: 2’1 cm.

- El índice de elongamiento (índice 1) ${ }^{11}$ es de $14^{\prime} 4$.

- El índice $2^{12}$ es de 3’3.

Es una pieza de gran tamaño en la que no se advierte decoración, que encaja bastante bien en el tipo 2a. Variante VA de la clasificación de Quesada,(QUESADA 1997: 358, 400401) grandes dimensiones entre $36^{\prime} 3$ y $65 \mathrm{~cm}$ de longitud, con una media de $48^{\prime} 3 \mathrm{~cm}$, lo que se aproxima bastante a este ejemplar, índice 2 en torno a 3 y hojas muy estrechas (media de $\left.3^{\prime} 5 \mathrm{~cm}\right)$ y sobre todo porque la anchura máxima de la hoja no está inmediatamente después de su arranque, sino dentro del primer quinto de su longitud (QUESADA 1997: 368369).Cronología: en la Alta Andalucía $1^{a}$ mitad s. IV a.C. En la mayoría de los casos aparece en yacimientos muy antiguos del s. V-IV a. C. (QUESADA, 1997: 369). Arma típicamente ibérica creemos que usada para el combate cuerpo a cuerpo y que se distribuye por una serie de necrópolis del Sudeste y la Alta Andalucía siendo el sitio mas cercano el de Almedinilla. (QUESADA, 1992: 123; VAQUERIZO, 1989: 227,235-237).

b) Museo Arqueológico de Baena. Número de registro 98/9/4.(Láms.10, 11, 12) (Fig. 8).

Esta pieza que se presenta doblada, creemos que debido a una intencionalidad ritual de inutilización, debemos encuadrarla en el mismo tipo que la anterior, 2a y la variante VA de Quesada (QUESADA 1997: 398). No se aprecia ranura longitudinal del cubo ni restos del capuchón interior o soldadura de cobre en el interior del cubo (QUESADA, 1997: 345; MIRO, REIG, 1997). Sus dimensiones son:

- Longitud máxima: $42^{\prime} 4 \mathrm{~cm}$.

- Longitud de la hoja: 30`9 cm.

- Longitud del cubo: $11^{\prime} 05 \mathrm{~cm}$.

- Anchura máxima de la hoja: 3’4 cm.

- Diámetro del cubo: 2`2 cm.

El índice 1 es mayor de 10, (12`4) y el índice 2 es de $2^{\prime} 7$. Presenta anillo de fijación, pero se le detecta un orificio del pasador, así como nervio de sección rectangular, redondeado en otros tramos con huellas de forja (MIRO, REIG, 1997). Por estas características encaja bastante bien en la variante VA., ya que la anchura máxima de la hoja se consigue en el primer quinto de su longitud, aunque la longitud total no llegue a la media de esta variante (48`3) está entre los 36’3 y $65 \mathrm{~cm}$ de los ejemplares de longitud mínima y máxima. Por el resto de características creemos que puede encajar bien en esta variante.

En cuanto a la distribución, cronología y paralelos cabe aplicar lo mismo que en el anterior ejemplar.

\footnotetext{
11 El índice 1 alude a la anchura relativa de la hoja en comparación con su longitud: longitud máxima de la hoja dividida por la anchura máxima de la hoja. Cuanto mayor es el índice 1 resulta mas alargada y estrecha (QUESADA, 1997: 357).

12 El índice 2 como la relación entre la longitud de la hoja y la del cubo: longitud de la hoja dividido entre longitud del cubo. (QUESADA 1997: 360).
} 


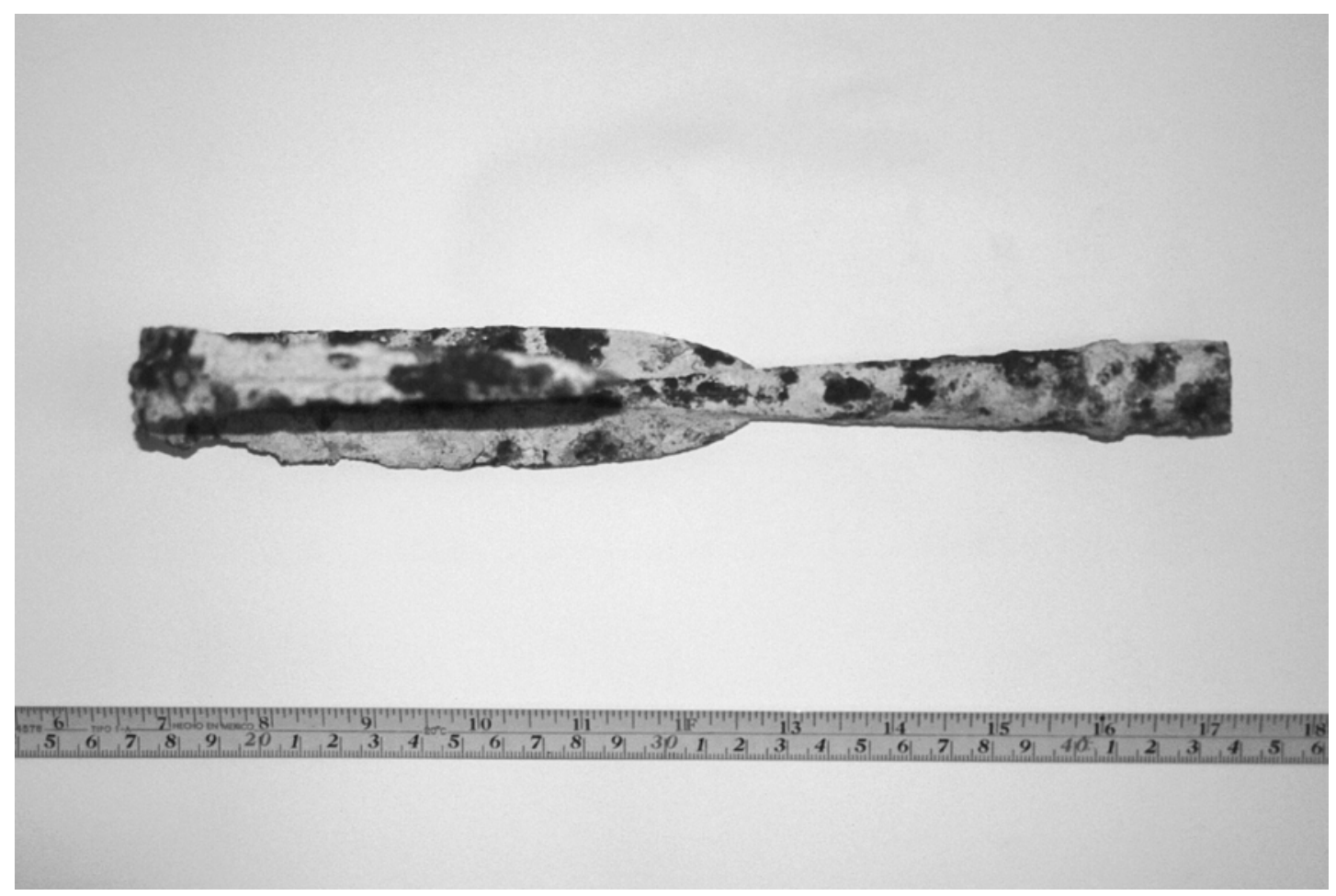

Lam. 10. Maharra de lanza doblada de forma intencionada. Museo Arqueológico de Baena.

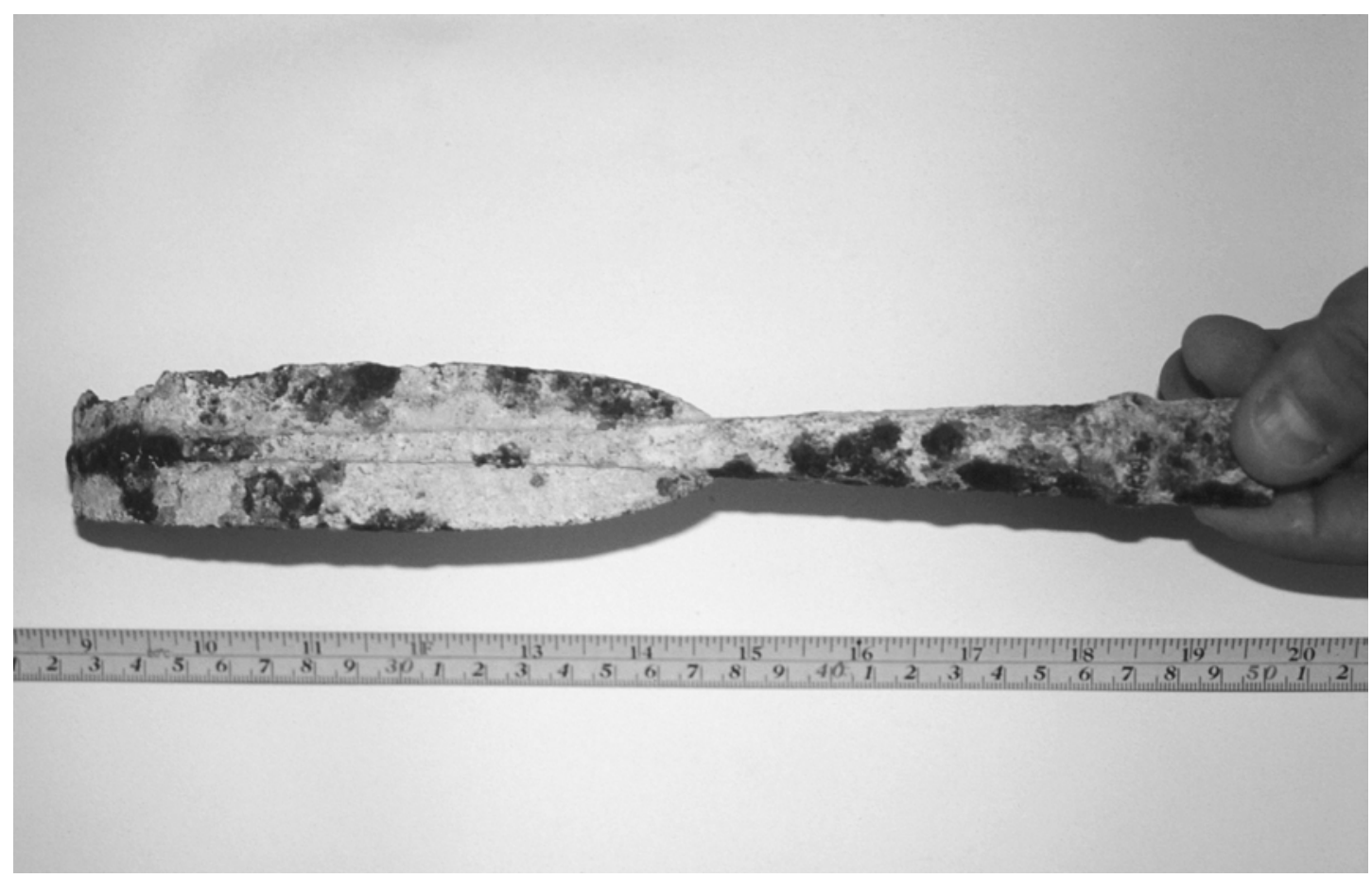

Lam. 11. Idem. 


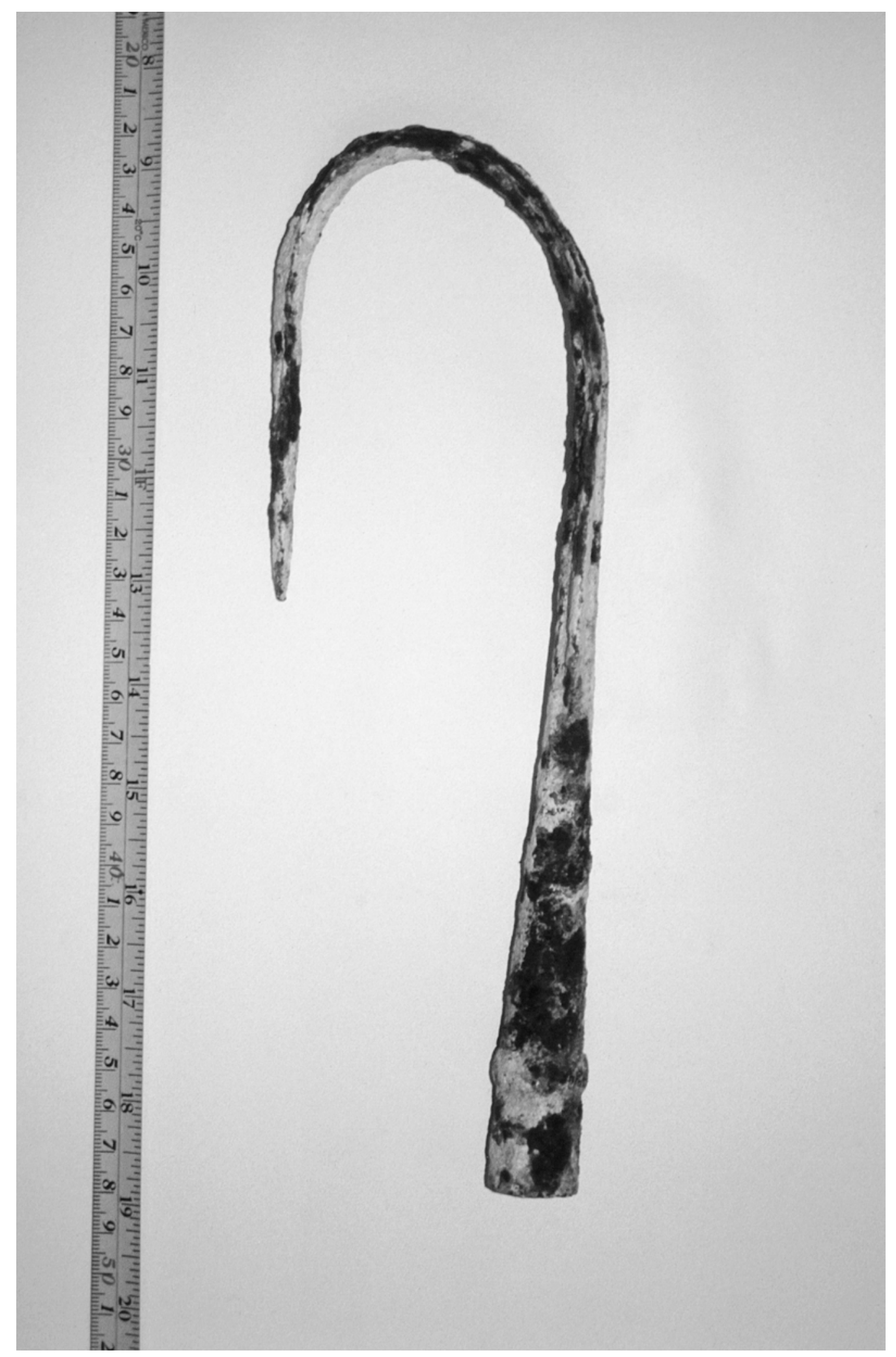

Lam. 12. Idem. 


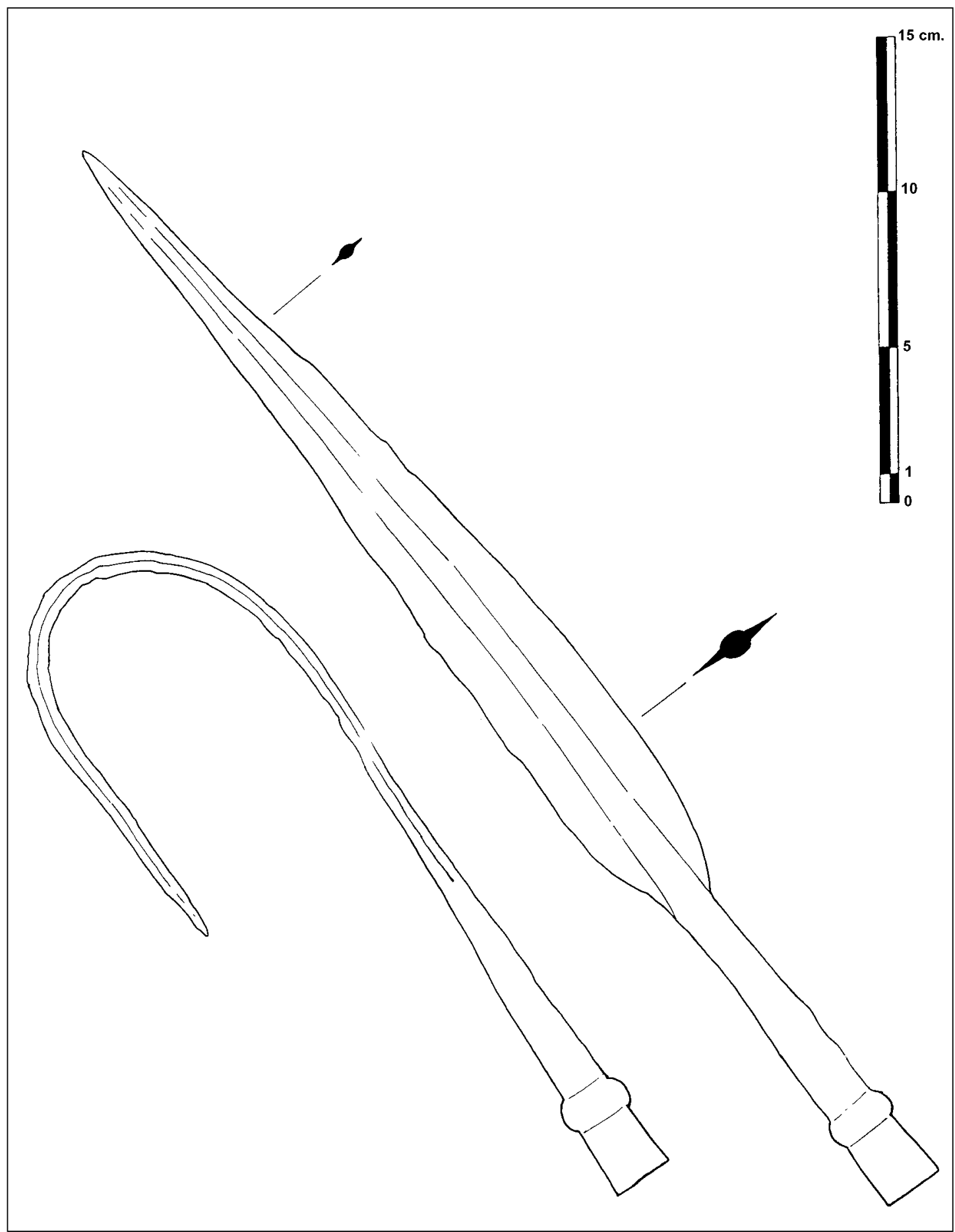

Fig. 8. Moharra de lanza. Museo Arqueológico de Baena. 

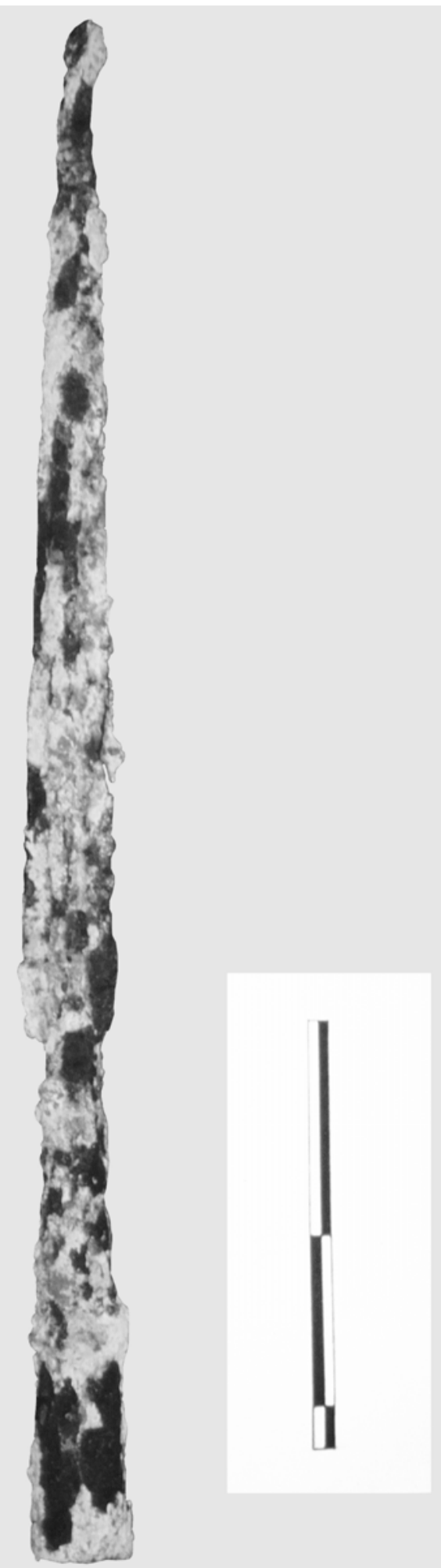

Lam. 13. Moharra de lanza. Museo Arqueológico de Baena. 
Gladius XXIII, 2003

UN LOTE DE ARMAS PROCEDENTE DE LA NECRÓPOLIS IBÉRICA

91

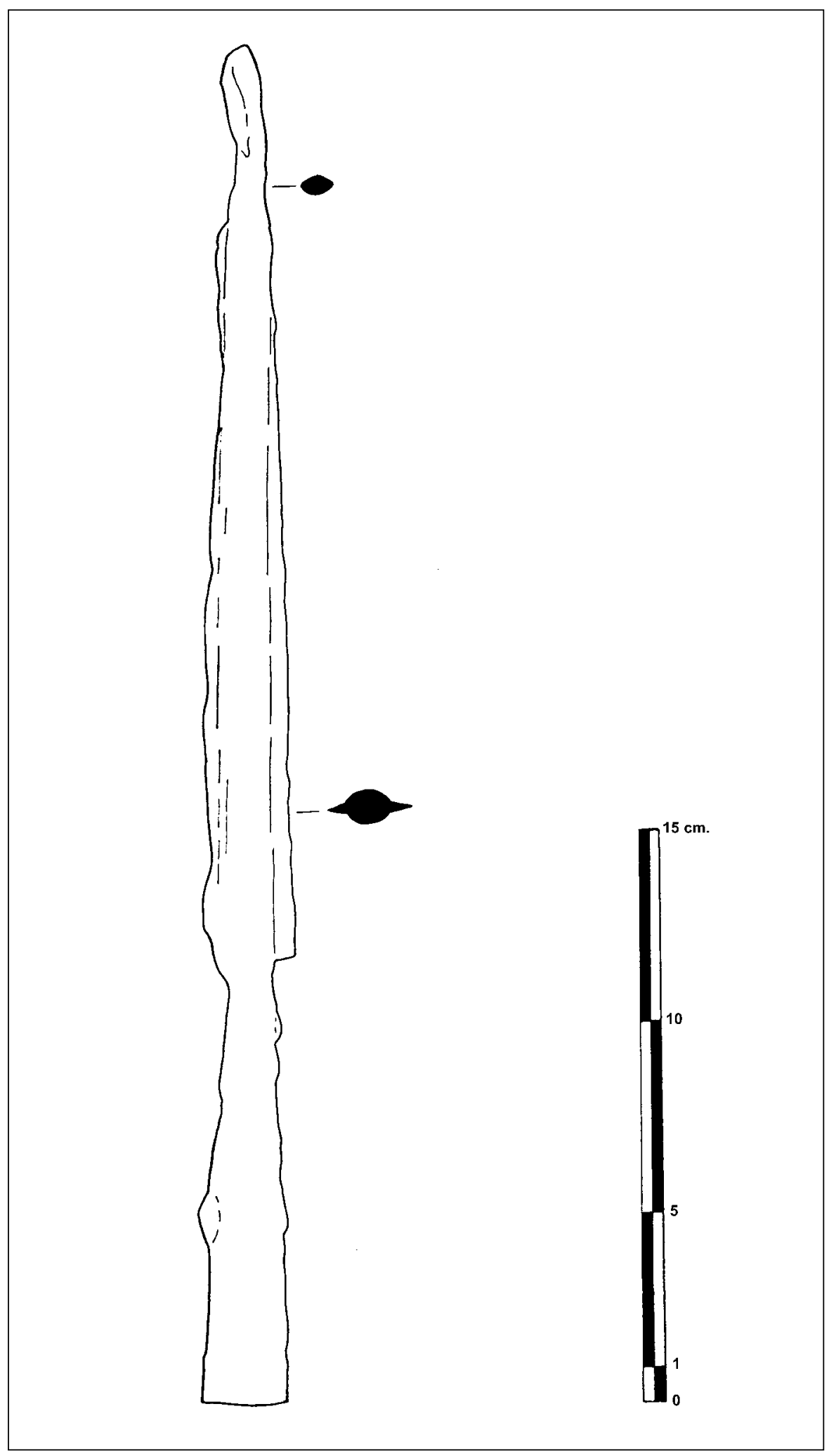

Fig. 9. Moharra de lanza. Museo Arqueológico de Baena. 


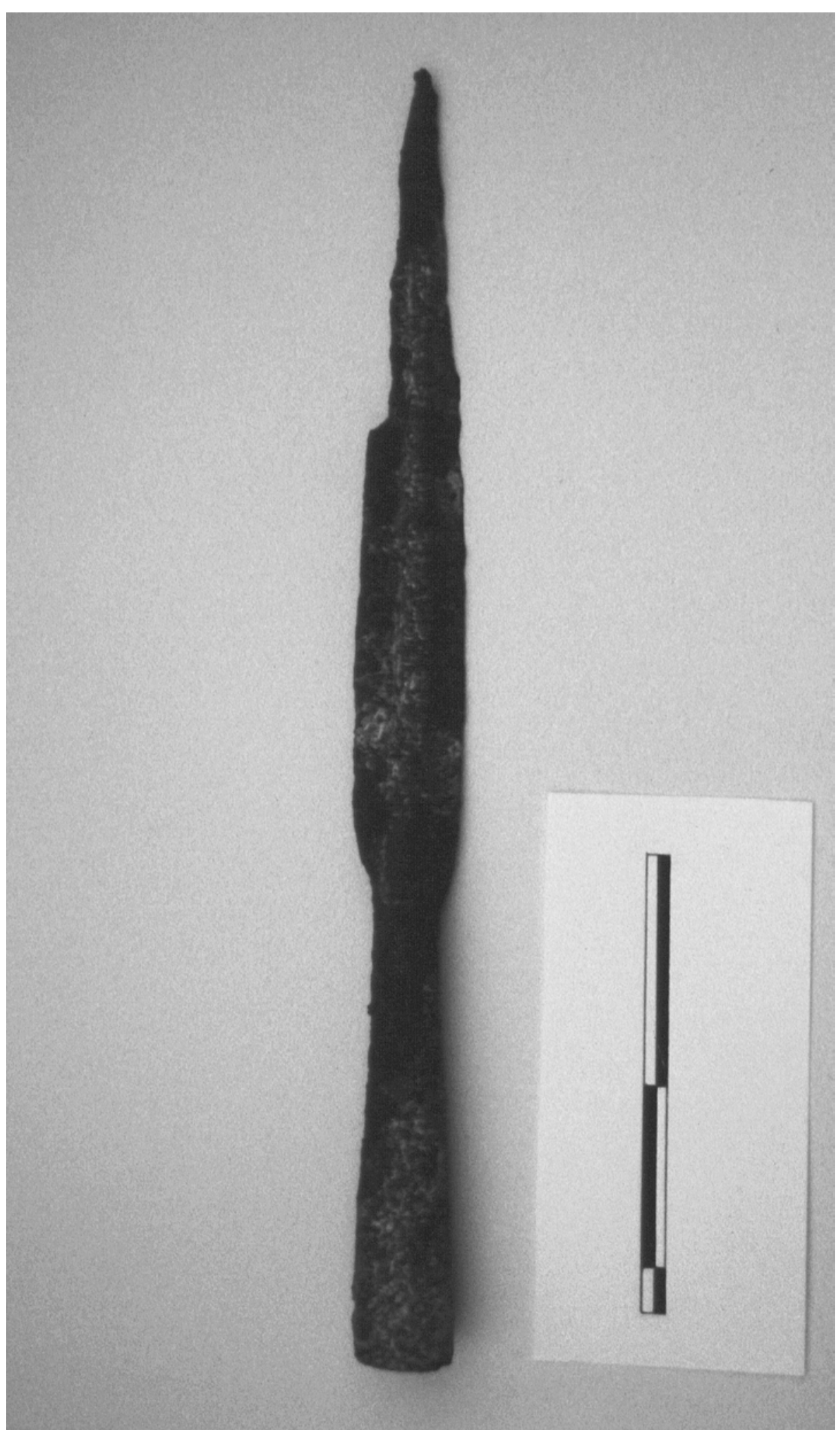

Lam. 14. Moharra de lanza. Museo Histórico local de Almedinilla. 


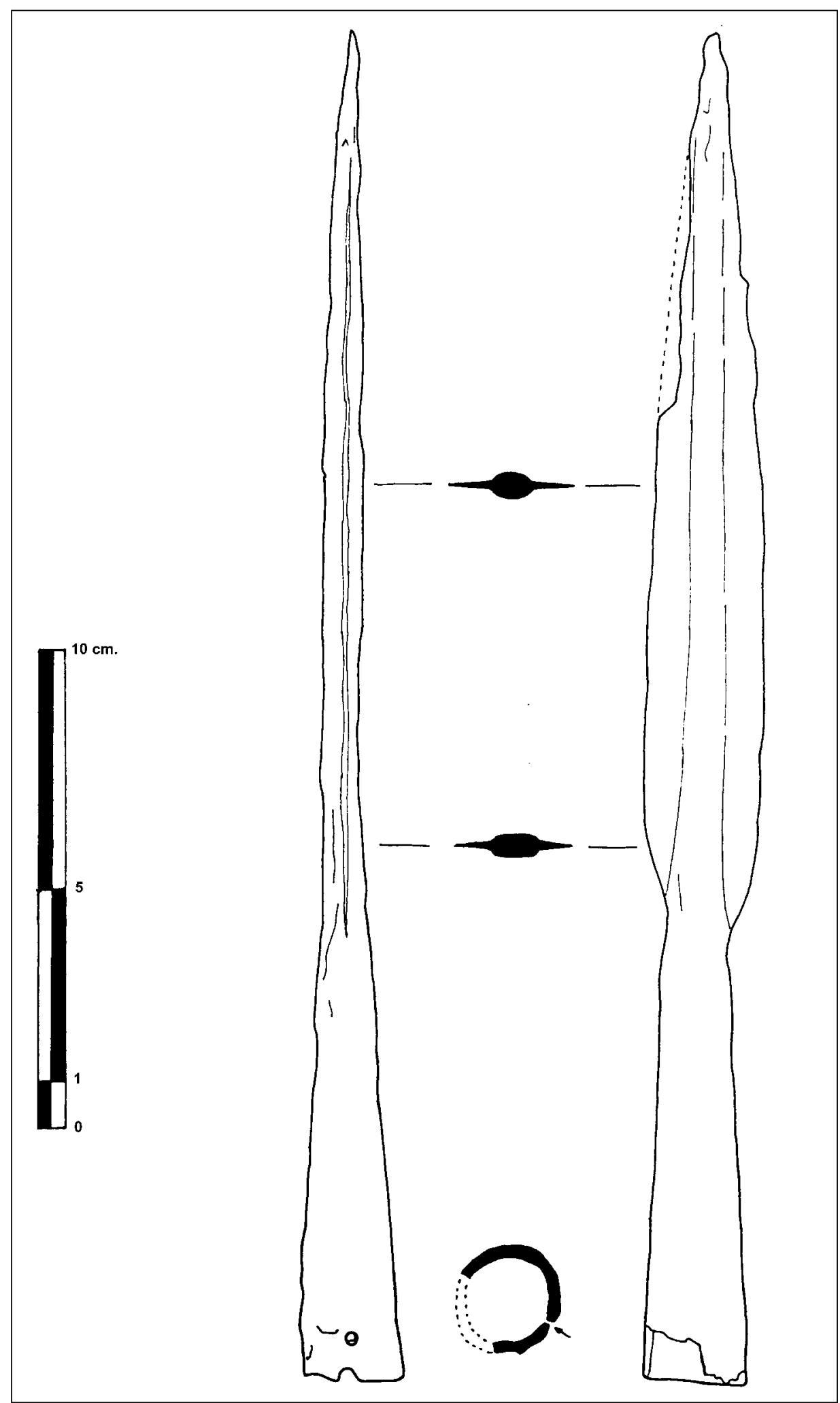

Fig. 10. Moharra de lanza. Museo Historico local de Almedinilla. 
c) Museo Arqueológico de Baena. Número de registro 98/9/6 (Lám. 13) (Fig. 9). Sus dimensiones son:

- Longitud máxima: $35^{\prime} 3 \mathrm{~cm}$.

- Longitud de la hoja: $23^{\prime} 7 \mathrm{~cm}$.

- Longitud del cubo: 11'6 cm.

- Anchura máxima de la hoja: 2`3 cm.

- Diámetro del cubo: 2`3 cm.

No se aprecia ni anillo de fijación al astil ni orificio del pasador.

La oxidación ha producido hinchazones apreciables en el cubo y en la punta. Uno de sus filos, sobretodo en su mitad inferior, está recortado.

Tipológicamente creemos que podría insertarse en el tipo 1, variante IA de Quesada (QUESADA, 1997: 363-361) cuyas hojas muy estrechas y alargadas con índice 1 mayor de 10 ( nuestro ejemplar mayor de 15) son casi perpendiculares a la base respecto al cubo, que es el rasgo más definitorio, como en nuestro caso, pese a que la longitud total no llegue a la media de esta variante $\left(46^{\prime} 7 \mathrm{~cm}\right)$,en parte quizá por merma de la punta, y el índice $2\left(2^{\prime} 7\right.$ ) tampoco llegue a la media, 3’1). El grueso nervio redondeado que se mantiene hasta casi el final de la punta sí se aprecia en este caso.

Corresponde a un arma para empuñar, no arrojadiza, para usar cuerpo a cuerpo, constituyendo parte importante de la panoplia peninsular desde el Orientalizante hasta avanzado el siglo V a. C. cuya dispersión se documenta en necrópolis de Andalucía (Illora, Estacar de Robarinas) Sureste, Levante Septentrional, Meseta Oriental, y Suroeste (QUESADA, 1997: $361)$.

d) Museo Histórico de Almedinilla .Número de registro 2002/15/6 (Lám. 14) (Fig. 10).

En buen estado pese a haber perdido parte de uno de los filos en su tercio final. Sus dimensiones son:

- Longitud máxima: $28 \mathrm{~cm}$.

- Longitud de la hoja: $18 \mathrm{~cm}$.

- Anchura máxima de la hoja: 2`4 cm.

- Indice 1, es mayor de 11.

El cubo, cuya longitud es de $10 \mathrm{~cm}$ y su diámetro de $2 ` 2 \mathrm{~cm}$ no presenta anillo de fijación pero si orificio del pasador, y le falta un fragmento en la base. Posee un acusado nervio de sección cuadrangular en la base que se torna irregular, casi redondeado más arriba. No se aprecia ranura longitudinal del cubo ni restos del capuchón interior o soldadura de cobre en el interior del cubo (QUESADA, 1997: 345; MIRO, REIG 1997).

Se trata de un arma mediana, destacando la esbeltez de su hoja, que hace subir a más de 10 el índice 1 y por su longitud total creemos que hay que encuadrarla en al tipo 6a y en la variante VIB de la clasificación de Quesada (QUESADA 1997: 400-401). Su distribución es muy amplia dentro y fuera del ámbito ibérico. El paralelo mas cercano se encuentra en Almedinilla (SCHÜLE, Taff. 76-77).

Su cronología es muy amplia del siglo V a.C. al siglo II a.C. Su mayor representación se da desde la segunda mitad del siglo IV a.C. hasta la Romanización (QUESADA 1997: 373). 


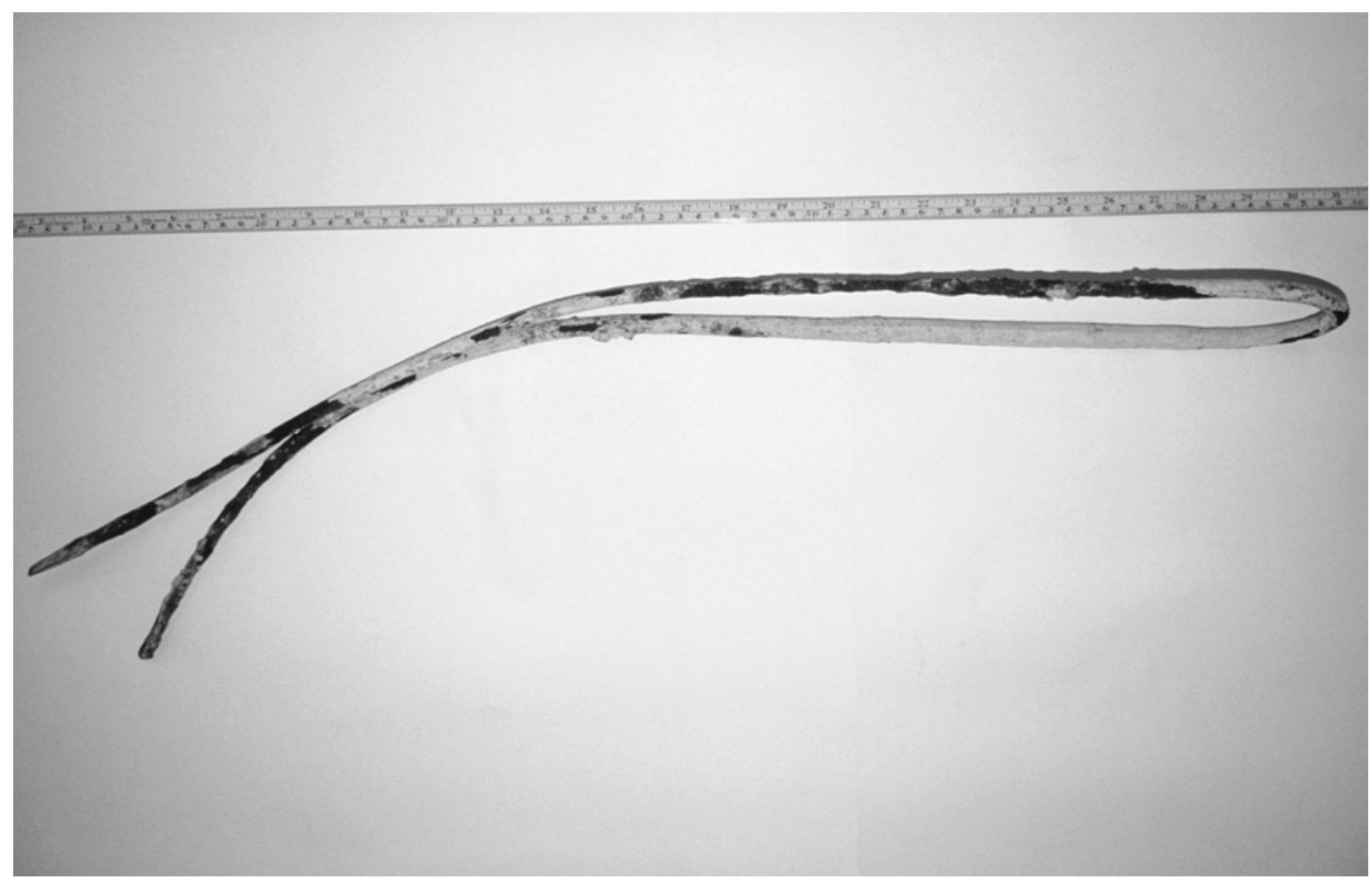

Lam. 15. Soliferreum doblado. Museo Arqueológico de Baena.

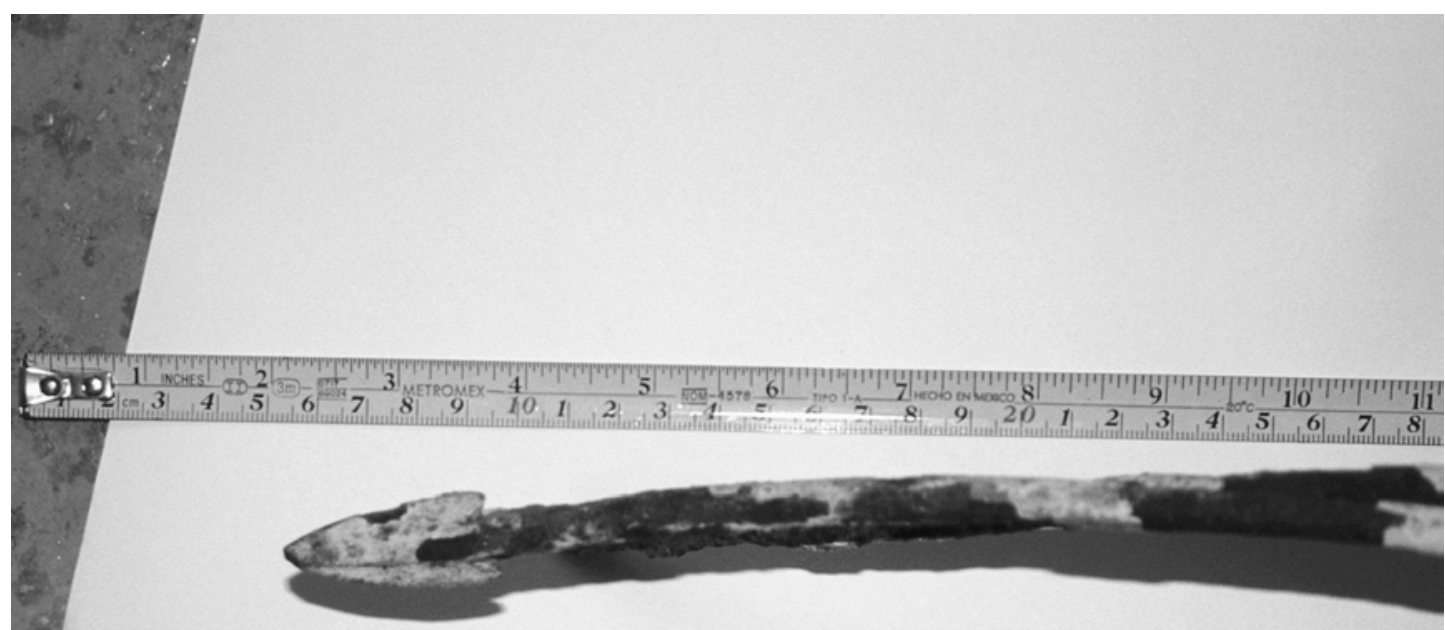

Lam. 16. Detalle de la punta. 


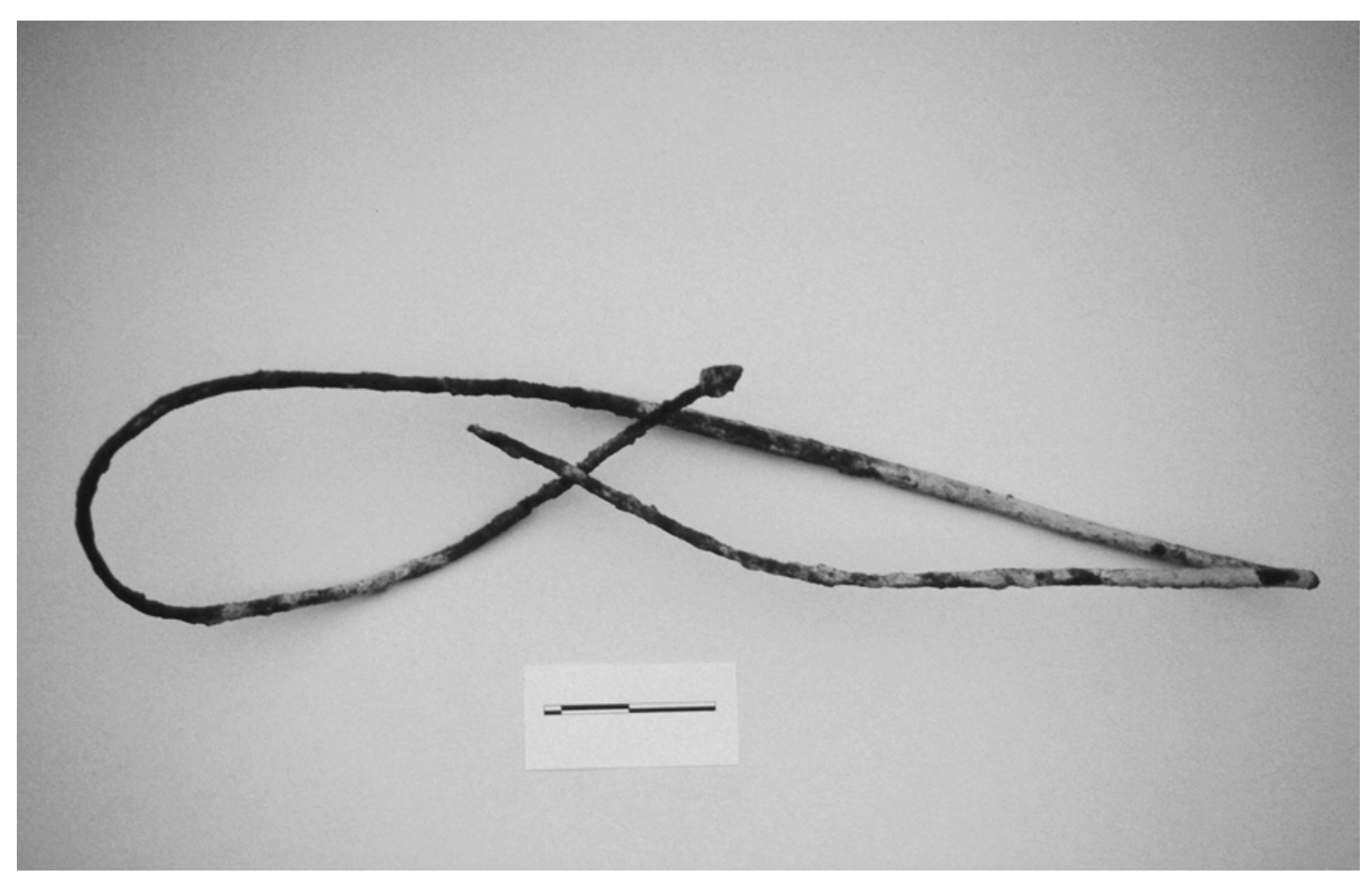

Lam. 17. Soliferreum. Museo Histórico local de Almedinilla.

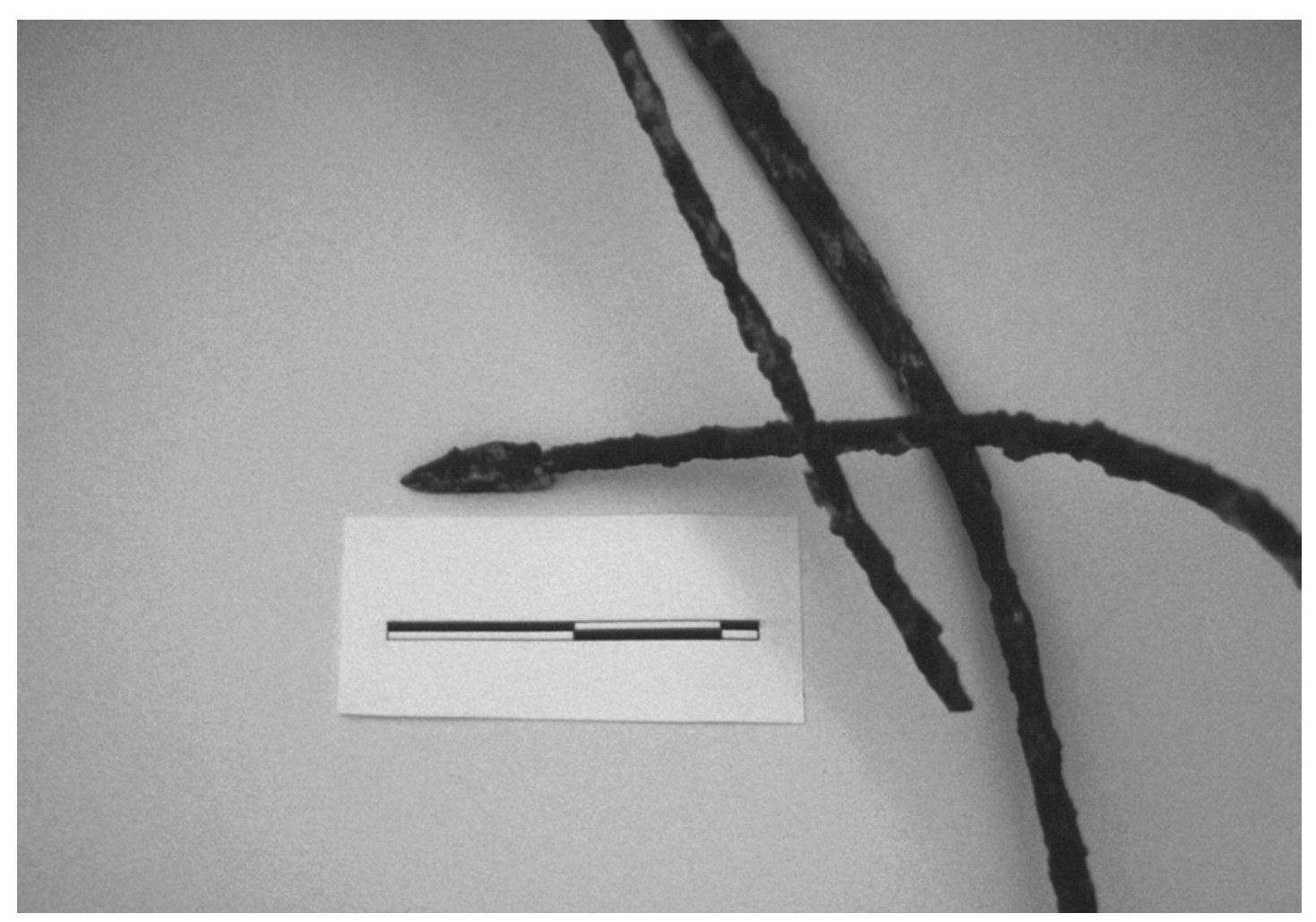

Lam. 18. Detalle de la punta. 


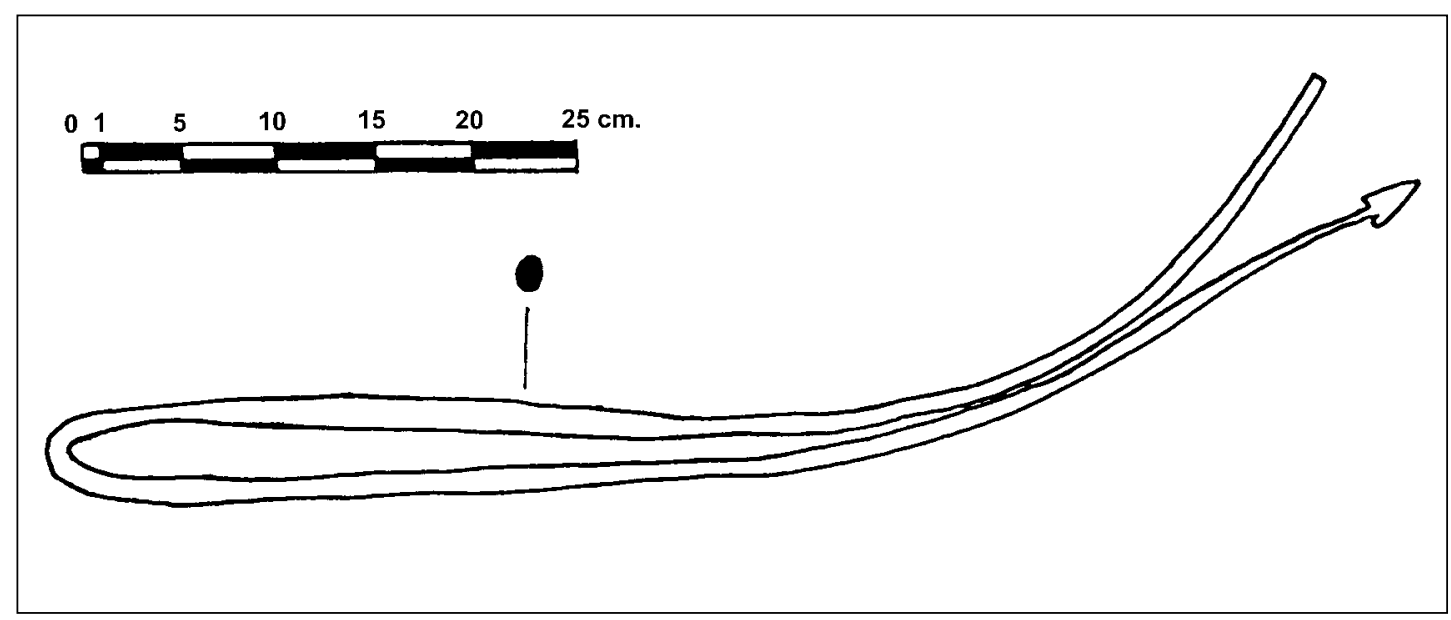

Fig. 11a. Soliferreum. Museo Arqueológico de Baena.

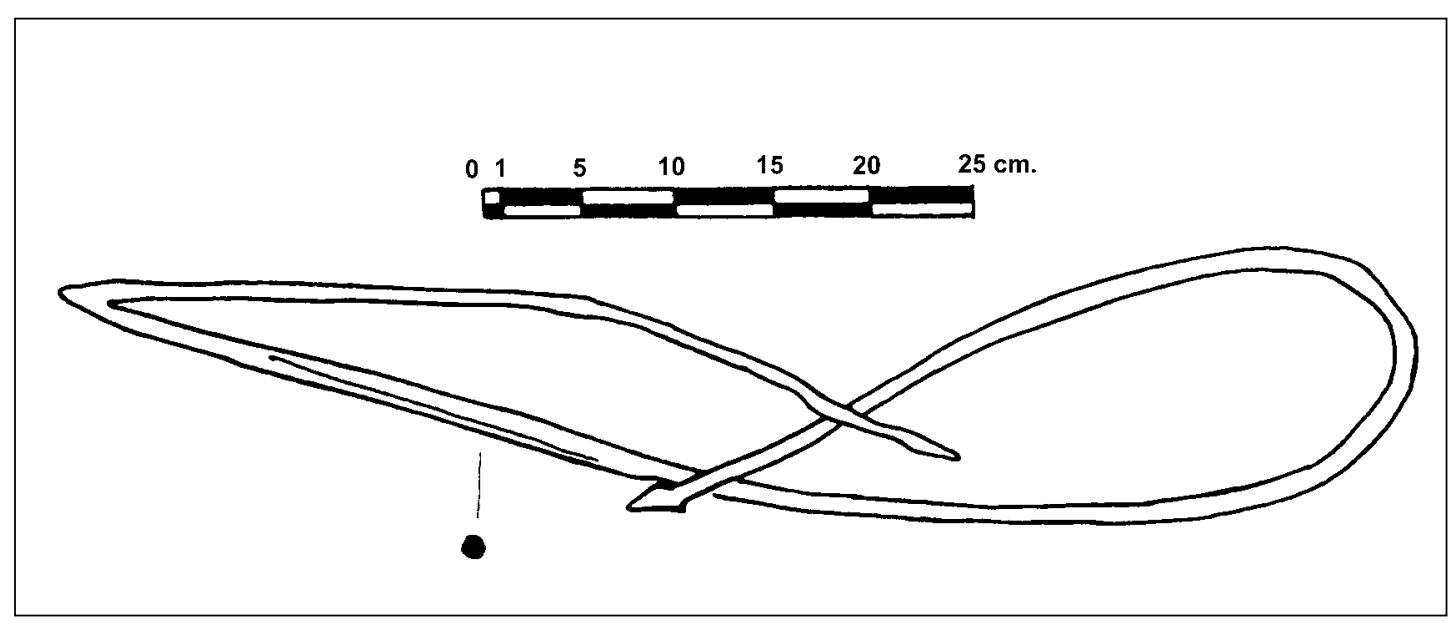

Fig. 11b. Soliferreum. Museo Histórico local de Almedinilla. 


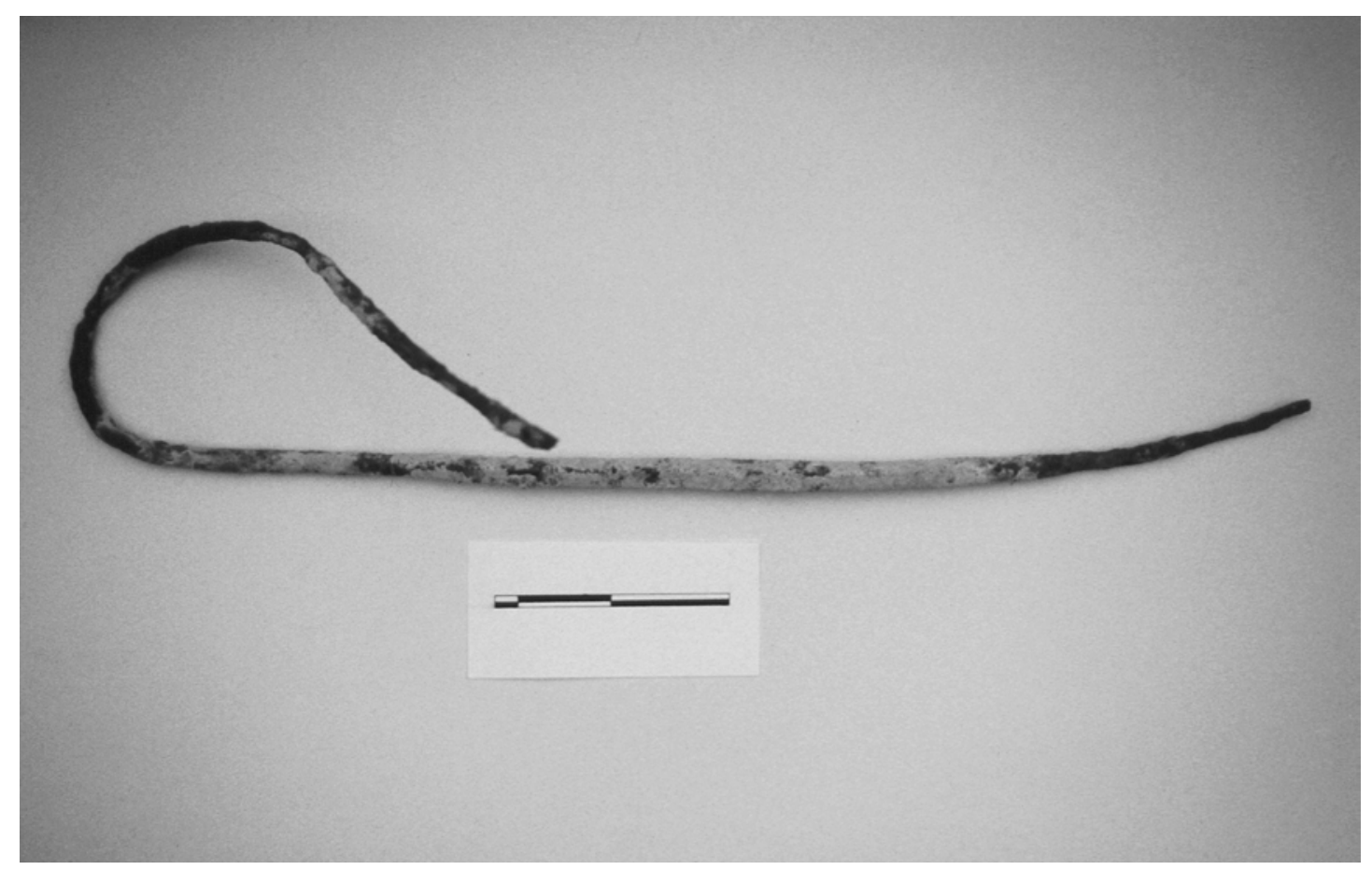

Lam. 19. Fragmento soliferreum.

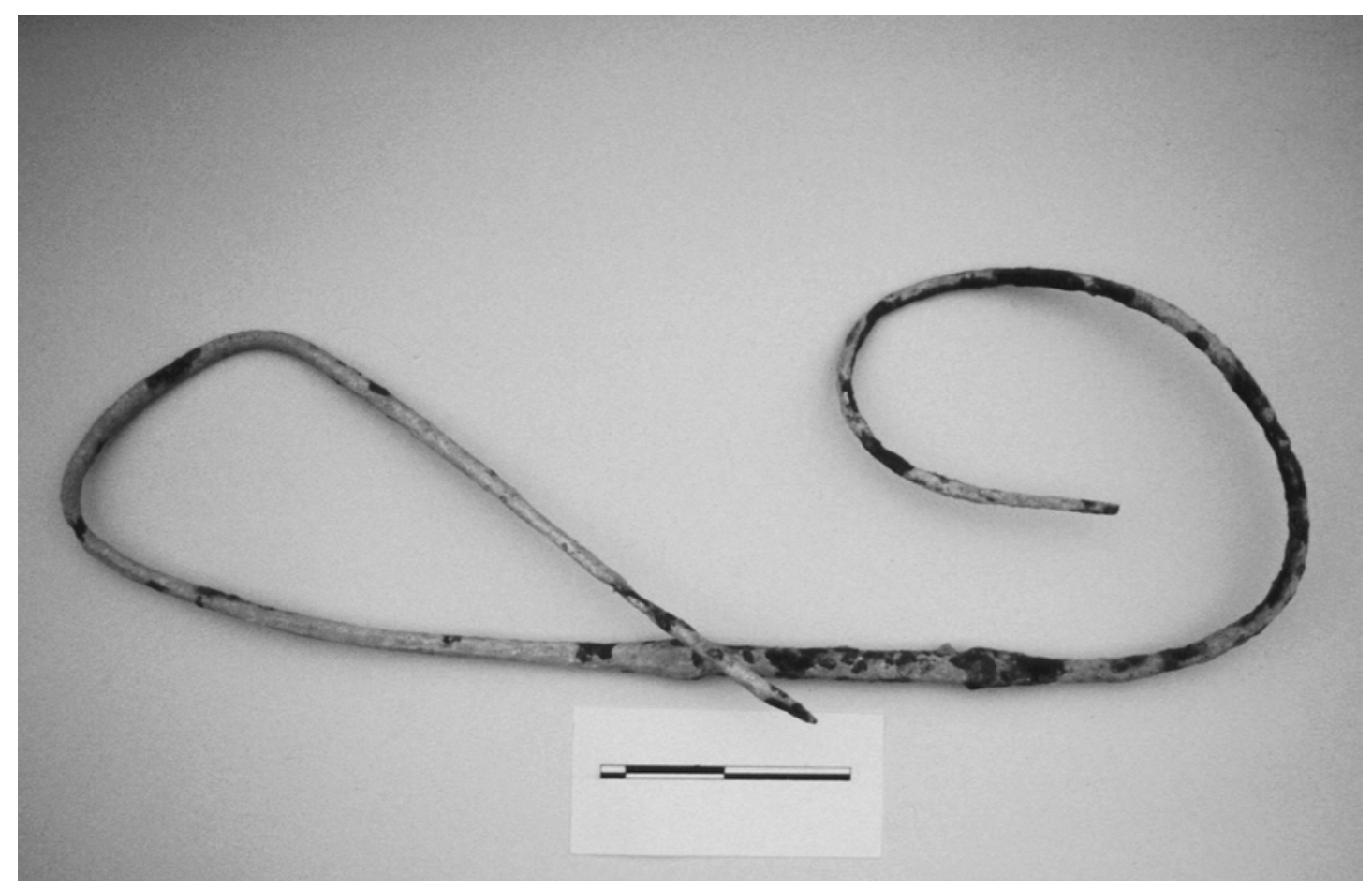

Lam. 20. Idem. 


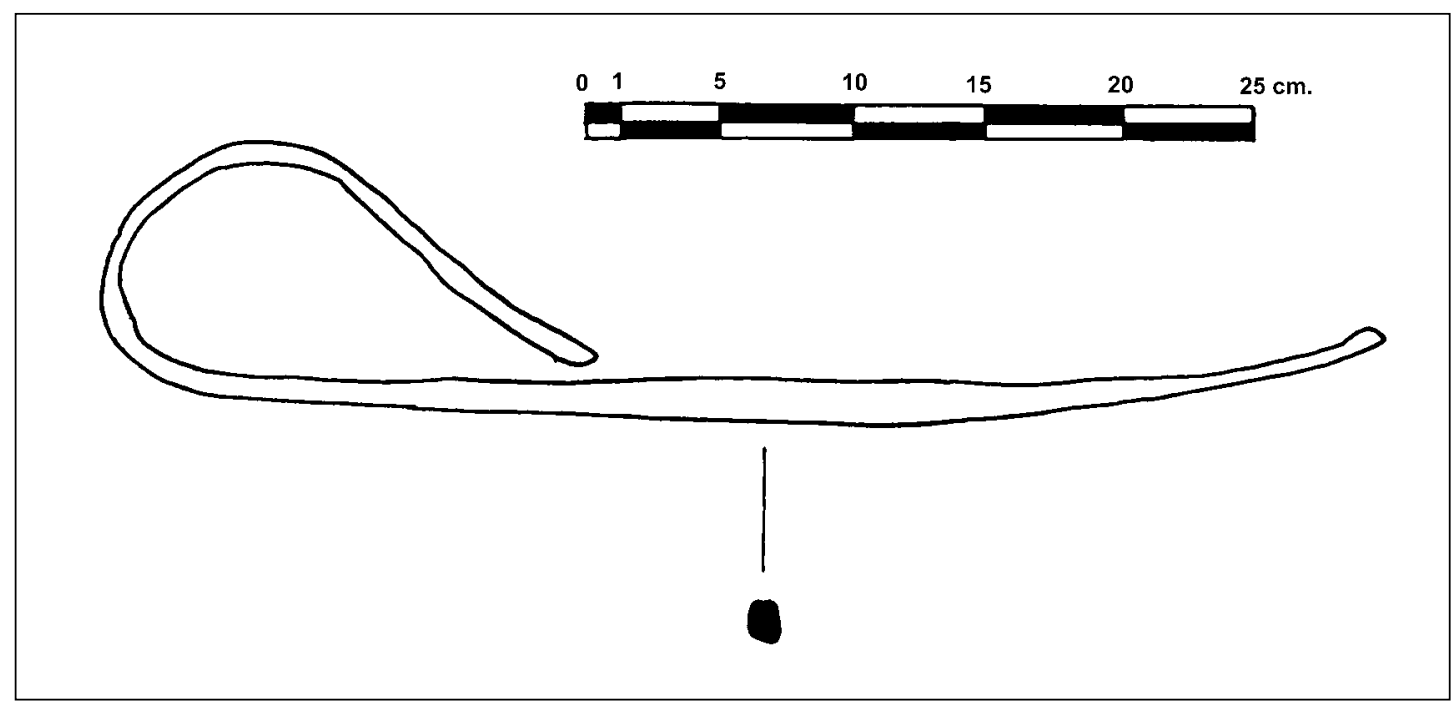

Fig. 12a. Fragmento de soliferreum.

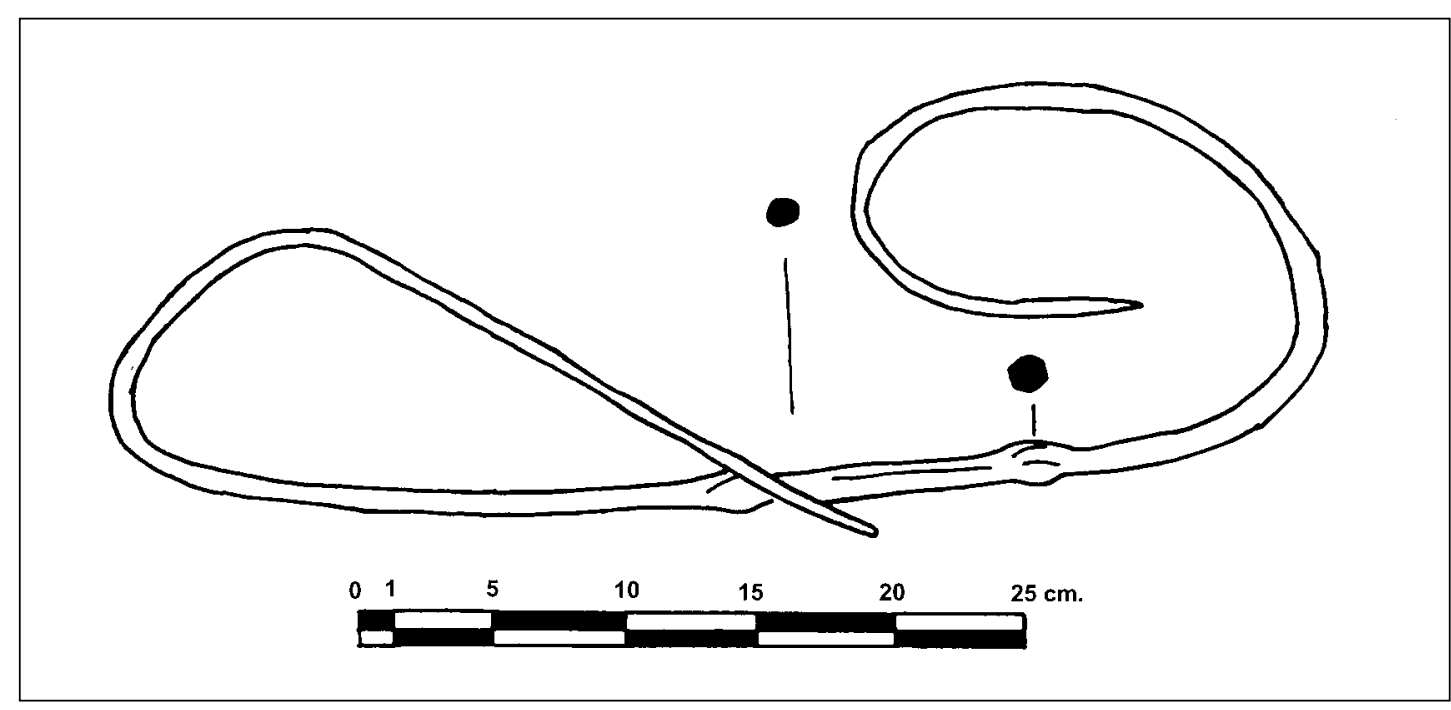

Fig. 12b. Idem. 


\section{SOLIFERREA.}

Cuatro piezas componen el conjunto de soliferrea. El primero de ellos, depositado en el Museo Arqueológico de Baena, (Número de registro 98/9/7) se trata de una barra de hierro de sección redondeada (Láms. 15, 16) (Fig. 11 a) con punta, oxidado y con incrustaciones terrosas que ha sido doblado por la mitad de forma intencionada como suelen aparecer en la mayoría de los hallazgos. Sus dimensiones son:

- Longitud total: $150 \mathrm{~cm}$.; quizá midiese algo más, ya que el extremo inferior se presenta biselado y no apuntado, como sería lo habitual.

El grosor varía de la zona central con éntasis para la parte del enmangue con un máximo de 1'35 de diámetro que desciende hacia la punta hastal 0’8 $\mathrm{cm}$ y en el extremo inferior hasta el $0^{\prime} 65 \mathrm{~cm}$. La punta, con aletas salientes que actúan como anzuelos, es la mas frecuente en la Alta Andalucía y se trata del tipo 3 de la clasificación de Quesada (QUESADA 1997: 31012).Si unimos el aspecto de la punta a la empuñadura obtenemos el tipo $3 \mathrm{~A}$ de la clasificación del mismo autor (QUESADA 1997: 314).

Las dimensiones de la punta son: Longitud:4'05 cm.; anchura: $1^{\prime} 7 \mathrm{~cm}$.

Las siguientes piezas están depositadas en el Museo Histórico de Almedinilla, de las que sólo una parece conservarse completa (Láms. 17, 18) (Fig. 11b) correspondiente al número de registro 2002/15/3.

Se encuentra doblado en forma de ocho, huella inequívoca de inutilización. Sus dimensiones son:

- Longitud máxima: $178 \mathrm{~cm}$.

- Longitud de la punta: $4^{\prime} 3 \mathrm{~cm}$.

- Anchura de la punta: $1 ’ 3 \mathrm{~cm}$.

El centro de gravedad, posterior, zona de enmangue engrosada con unos 1'3 cm durante $25 \mathrm{~cm}$, presenta sección redondeada, al igual que el resto de la pieza con varios tramos de sección irregular con marcas de golpes de forja (QUESADA 2001).Siguiendo la clasificación de F. Quesada (QUESADA 1997: 313-14) lo insertamos en un tipo de punta 2 A con puño A.

El siguiente fragmento (número de registro 2002/15/5) (Lám. 19) (Fig. 12a) pieza sin extremos, por lo tanto sin punta, mide $90 \mathrm{~cm}$ de longitud; el grosor máximo de la zona de enmangue, que recorre unos $23^{\prime} 5 \mathrm{~cm}$ es de $1^{\prime} 1 \mathrm{~cm}$. La empuñadura como en el caso anterior es del tipo A (QUESADA 1997: 319).

El último fragmento(número de inventario 2002/15/4) (Lám. 20) (Fig. 12b.) más largo que el anterior, que mide $137^{\prime} 1 \mathrm{~cm}$ carece también de punta con los extremos retorcidos, abarca una longitud de $14^{\prime} 5 \mathrm{~cm}$ a modo de enmangue limitado por dos engrosamientos a ambos lados de sección redondeada y grosor de 1'6 cm. Se aprecian huellas de forja que dejan en algunos tramos planos y secciones irregulares. Creemos que la empuñadura corresponde al tipo C de F. Quesada (QUESADA, 1997: 310).

Difícilmente se puede intentar una aproximación cronológica con estas piezas aunque en Andalucía Oriental abundan los soliferrea sobretodo a partir del siglo IV-III a. C. (QUESADA 1997: 315). 


\section{MANILLA DE ESCUDO.}

Museo Histórico de Almedinilla. Numero de registro 2002/15/1 (Láms. 21, 22) (Fig. 13).

Se conserva incompleta, con la empuñadura prácticamente entera y fragmentos de las aletas, sobre todo de una. Las medidas por tanto son parciales: ${ }^{13}$

- LIE (longitud interior de la empuñadura): $10 \mathrm{~cm}$.

- Base de las aletas: ${ }^{14}$

- Anchura: 4’6 cm.

- Grosor de la empuñadura: 1’7 cm, formada por una lamina vuelta sobre sí misma y por tanto hueca.

- Grosor de la aleta: 0’2 cm.

Resulta difícil adscribir este ejemplar a uno de los grupos tipológicamente definidos, pero por la gran anchura de la base de las aletas, de la cual se intuye un largo desarrollo, nos inclinamos a modo de hipótesis a insertarla en el grupo III de Quesada (QUESADA 1997: 503) sin poder definir tipo ni variante.

Este grupo se extiende por el Sudeste y Alta Andalucía a partir de comienzos del siglo IV a. C. Los ejemplos más cercanos los hallamos en Almedinilla y Fuente Tójar (QUESADA 1997: 505).

\section{CONCLUSIONES}

Pese a que el material que estudiamos tiene un carácter de hallazgo fortuito ${ }^{15}$, por tanto descontextualizado arqueológicamente, entendemos que supone una interesante aportación al registro de armas de la II Edad de Hierro, halladas al oeste de la línea Andújar-Almedinilla ya señalada por F. Quesada (QUESADA 2001: 101 y QUESADA, 1992: 116).Este mismo autor publicó recientemente un ajuar procedente igualmente del yacimiento de Torremorana que siguiendo la línea interpretativa que él plantea, consideramos hay que valorar los materiales que aquí presentamos en un ambiente funerario, es decir que formarían parte de ajuares de tumbas, y aparecerían asociados a una serie de restos cerámicos- cerámica ibérica pintada- también documentados en el yacimiento ${ }^{16}$.

En este sentido y, aunque, según hemos apuntado en algunas notas del presente trabajo, el material cerámico a que nos referimos lo tenemos en fase de estudio, avanzamos aquí algunos datos derivados de una primera aproximación a su análisis, en virtud de la significación que puedan encerrar de cara a las más adecuada interpretación de las piezas armamentísticas estudiadas. Destaca especialmente en este grupo un ejemplar de cerámica ática de barniz negro ${ }^{17}$, objeto muy significativo que suele ser amortizado y hallado en muchas necrópolis ibéricas del Sureste, Levante y Alta Andalucía, como parte del ajuar funerario: se trata de una pátera de $12^{\prime} 4 \mathrm{~cm}$ de diámetro exterior y $6^{\prime} 95 \mathrm{~cm}$ de diámetro del pie, $4^{\prime} 65 \mathrm{~cm}$ de altura y 1’80 de pie; presenta en su interior decoración a base de cuatro palmetas impresas

\footnotetext{
13 Seguimos a F. Quesada en la observación de las dimensiones básicas que presenta en QUESADA 1997: 495.

14 E. CUADRADO así denomina a dicha parte (CUADRADO 1989: 83).

15 Ver nota 3.

16 Donados al Museo Histórico Local de Almedinilla, en estudio junto con otros materiales ya citados del Museo Arqueológico de Baena. Ver nota 6.

17 Encontrada según su «hallador» también en el yacimiento de Torremorana y depositada en el Museo Arqueológico de Baena con número de registro 98/9/3.
} 


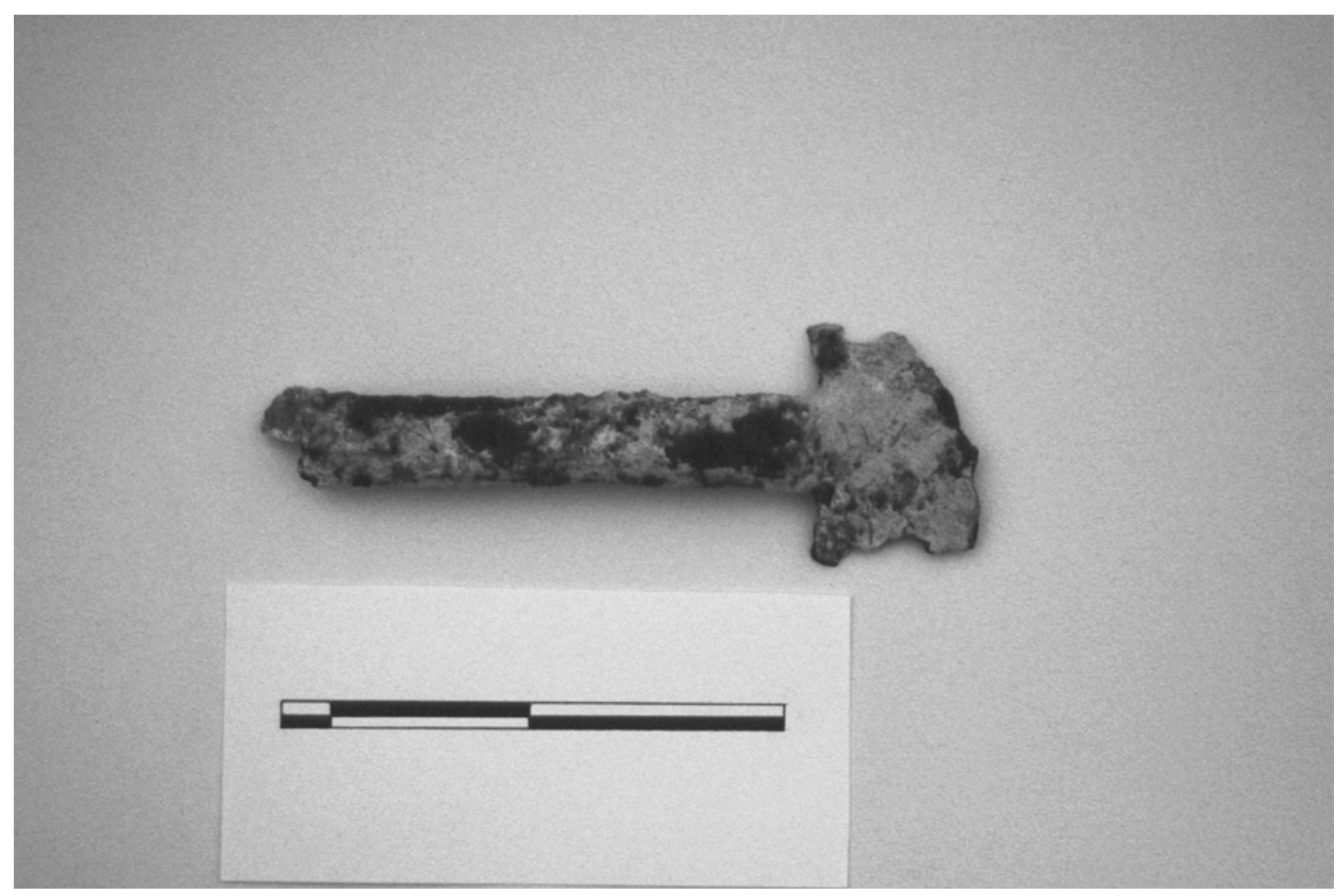

Lam. 21. Manilla de escudo.

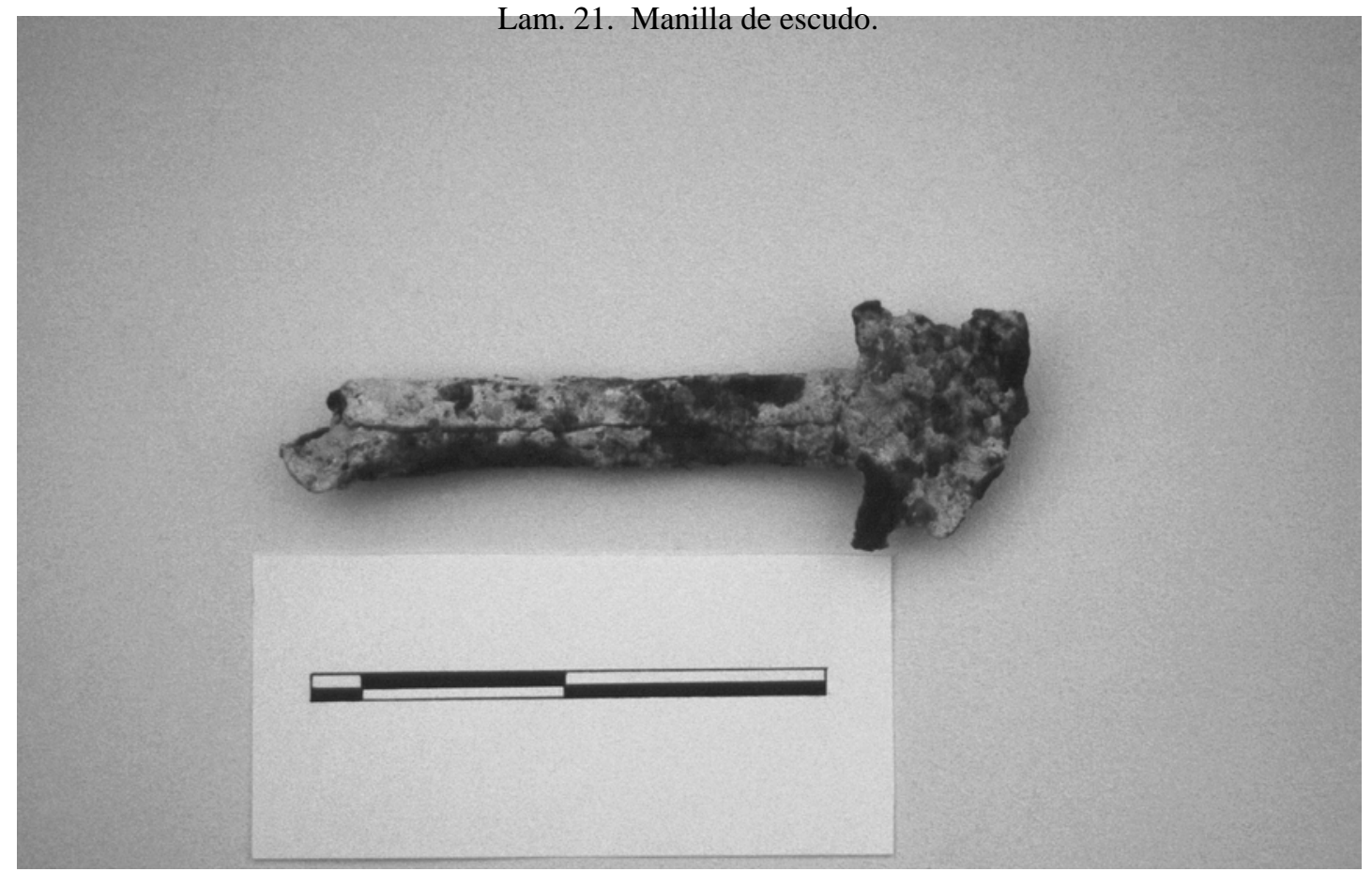

Lam. 22. Manilla de escudo. Observese detalle de la ranura. 


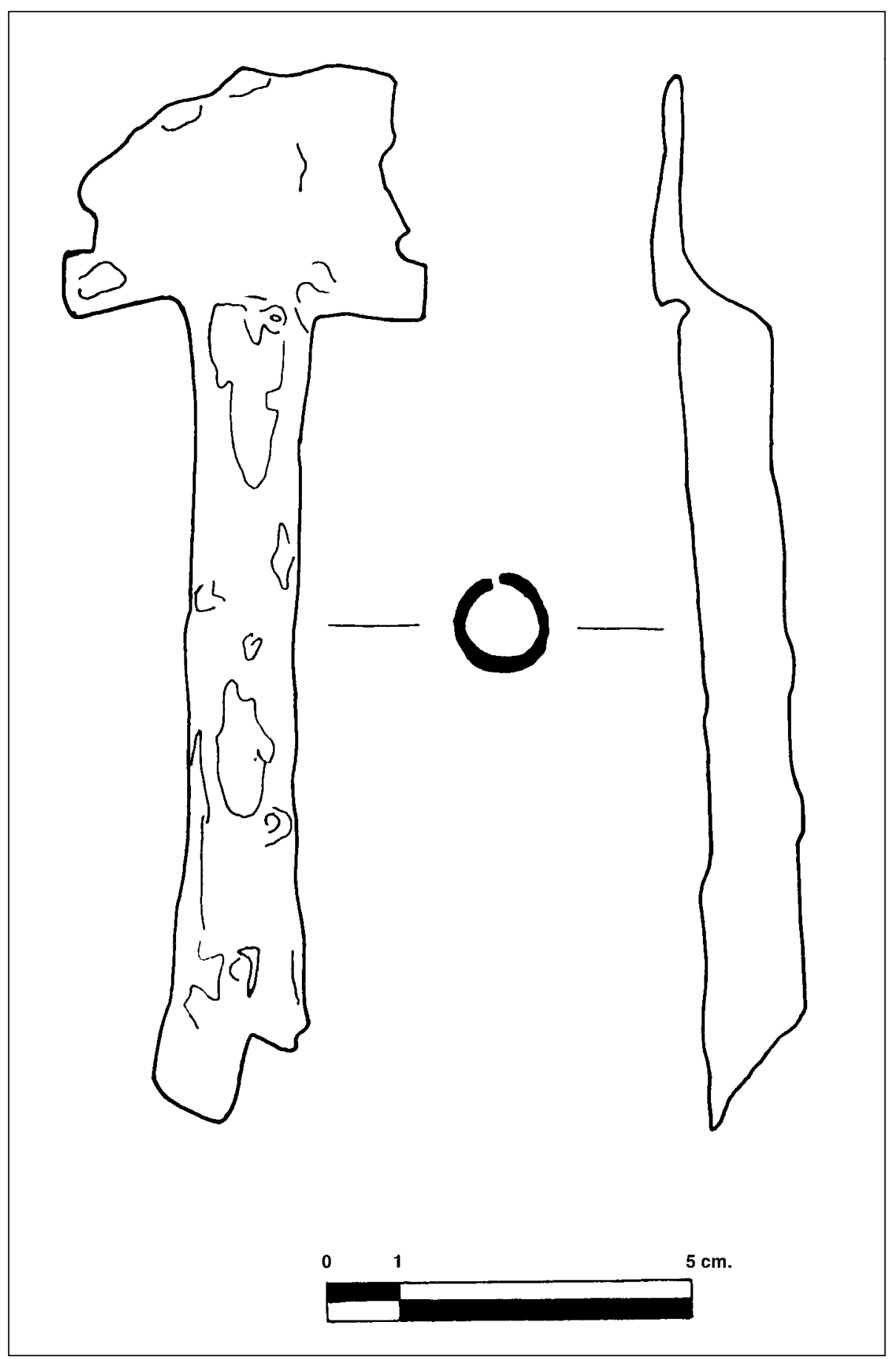

Fig. 13. Manilla de escudo. 


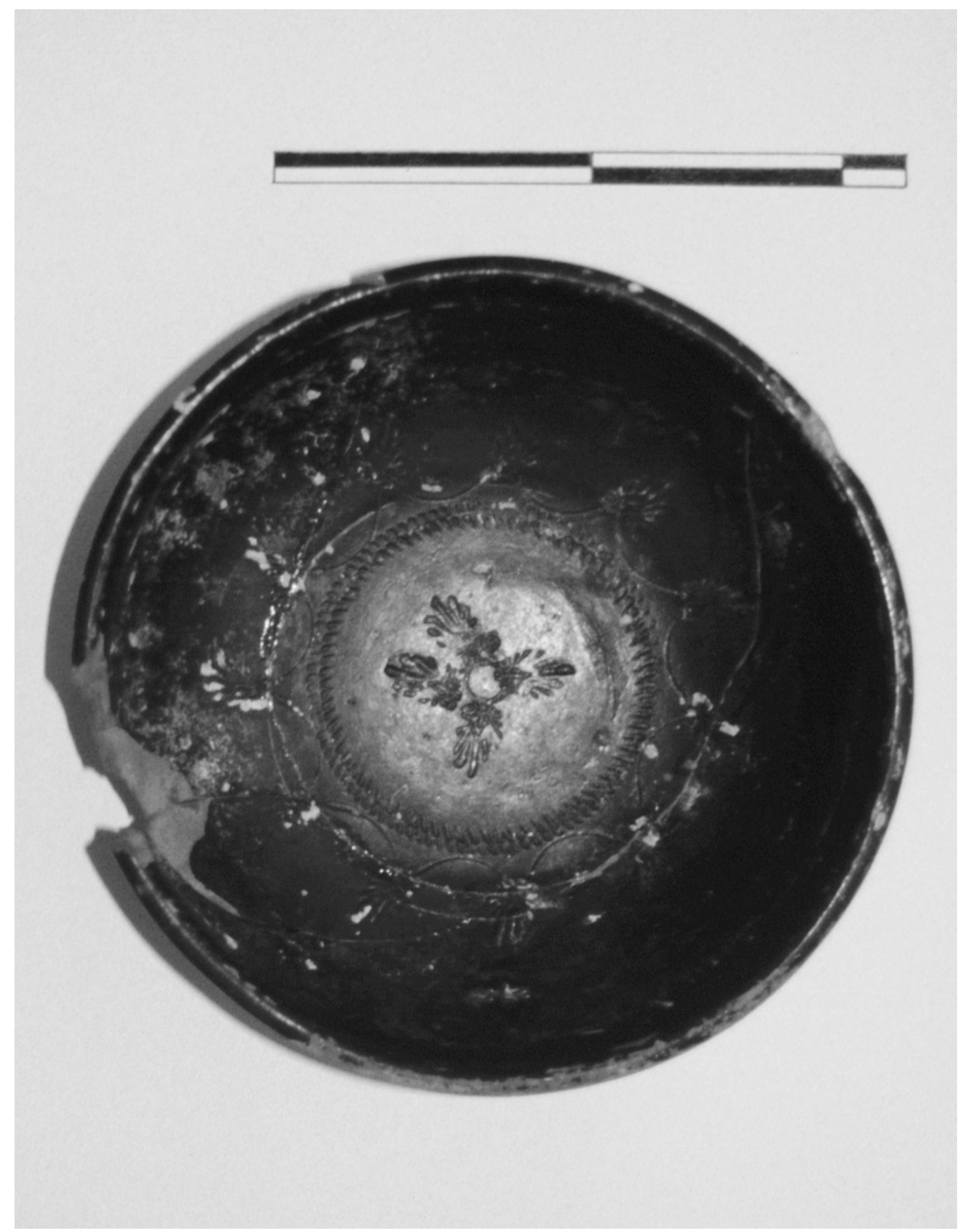

Lam. 23. Interior patera ática de barniz negro. Museo Arqueológico de Baena. 


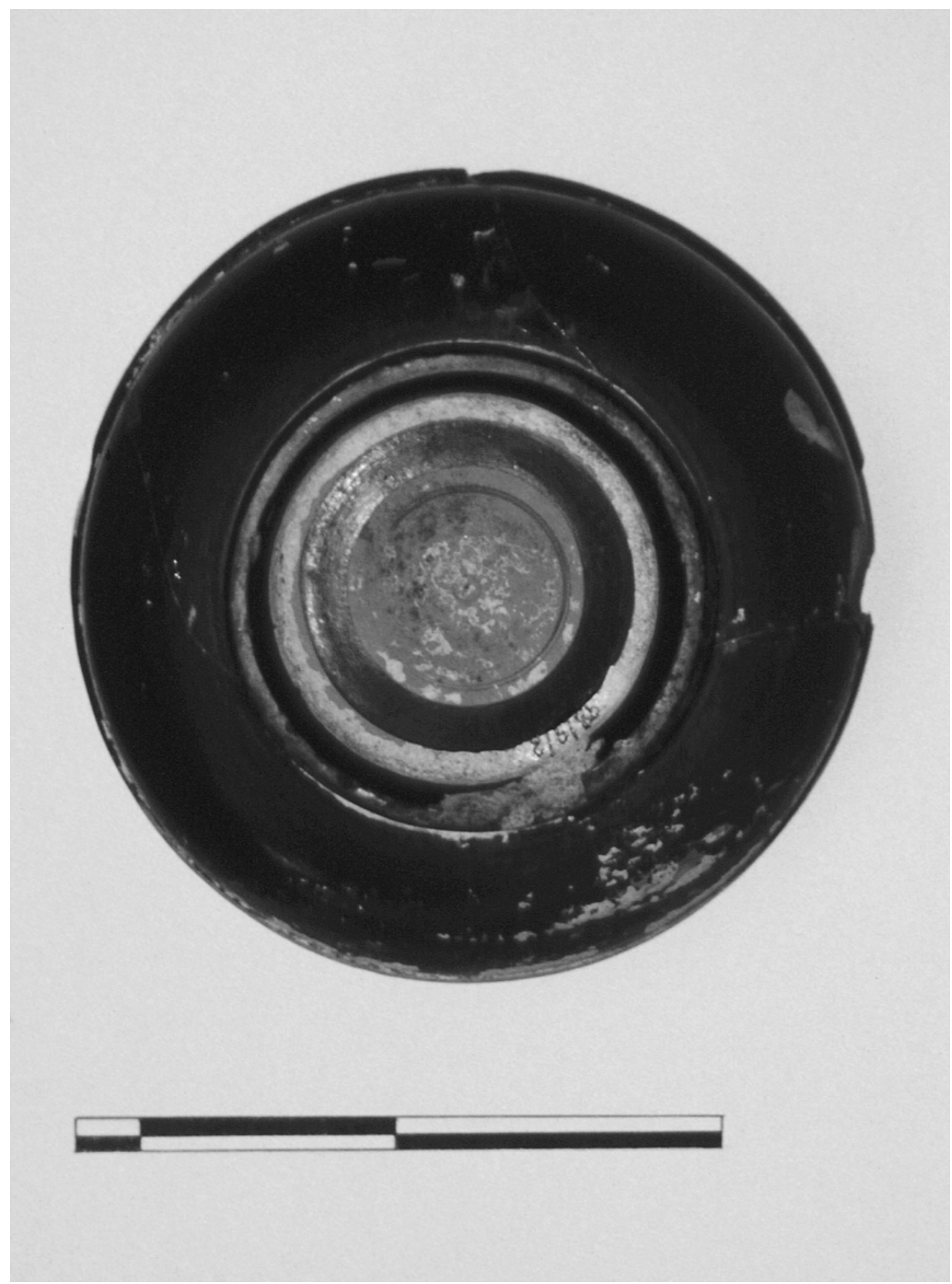

Lam. 24. Idem. parte externa con pie. 


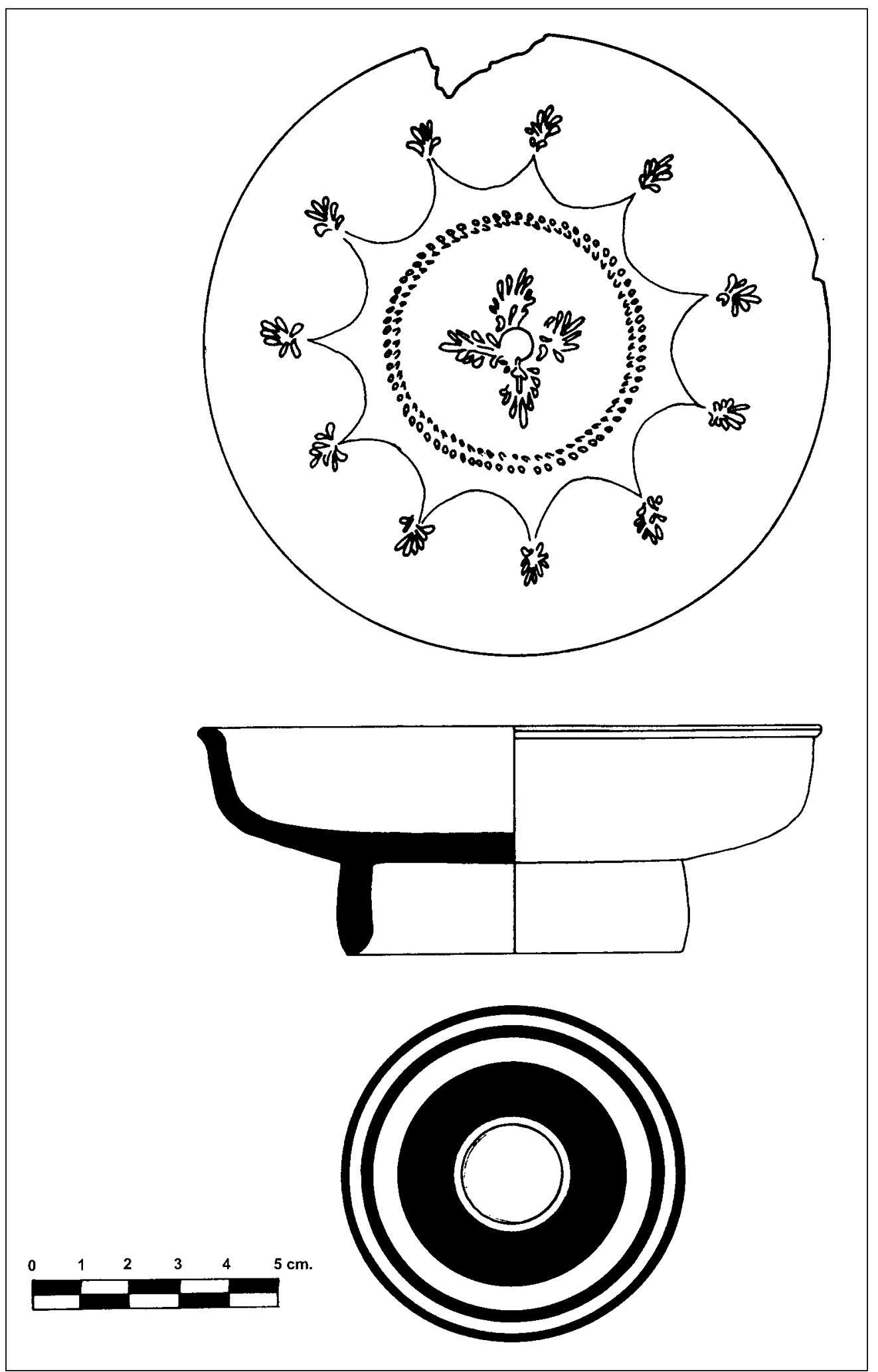

Fig. 14. Patera atica de barniz negro. 
agrupadas en el centro rodeadas por dos círculos de incisiones o estrías hechas a la ruedecilla (ARRIBAS et alii, 1987: 259-261) y a su vez por 11 palmetas también impresas enlazadas (CUADRADO, 1963: 111) Es una forma Lamboglia 22 que aparece, por ejemplo, en la necrópolis de El Cigarralejo, en aproximadamente una veintena de tumbas (CUADRADO, 1987). Se trata del tipo pequeño, que aunque no obedece exactamente a la decoración que describimos, sí cumple el mismo esquema decorativo de palmetas «enlazadas» (en los tipos grandes). Esta forma 22 se data en la citada necrópolis en el primer y segundo cuarto del siglo IV a.C. No conseguimos encuadrar la decoración de esta pieza con ninguna de los «talleres» que nos ofrece el repertorio de El Sec, aunque la forma de las palmetas guardan cierta semejanza con las del «Taller» Sec-3, (ARRIBAS et alii, 1987: 263-264). Más cercano a nuestro yacimiento, en Castellones de Ceal también se documenta esta forma (ADROHER, LÓPEZ, 1992: 309).

De lo hasta aquí afirmado, se desprende la constatación dentro del yacimiento de Torremorana de una zona de necrópolis, aparte del oppidum o zona de «hábitat», situado algo más al norte. Este carácter de necrópolis ibérica viene probado ,así lo creemos, por los materiales expuestos, plenamente encuadrables en el ámbito cultural ibérico ${ }^{18}$.

Desde el punto de vista del marco cronológico, el estudio de los materiales aporta la idea de un uso temprano y temporalmente amplio de la zona de enterramientos. Así induce a pensar la consideración de la espada de frontón y la moharra de lanza, del tipo 1 IA como materiales antiguos de entre los siglos VI-V a.C., para continuar con las moharras de lanza del tipo 2, la manilla de escudo y la falcata, que creemos mas reciente y terminar con la punta del tipo 6 a con unos márgenes cronológicos más amplios, al igual que los soliferrea. Un apéndice cronológico al respecto podría ser la pátera de barniz negro antes citada.

Por ello, estimamos que estos materiales se incardinarían en un contexto funerario que podría abarcar al menos los siglos V - IV a.C. ( $2^{\mathrm{a}} \frac{1 / 2}{\mathrm{~s}}$. V-1 $1 / 2 \mathrm{~s}$. IV a.C. tratando de ser más precisos), y que encajan holgadamente en aquellas que dan las prospecciones del yacimiento de Torremorana a tenor de las características tipológicas de las cerámicas documentadas (Orientalizante - siglo I d.C.) (MURILLO et alii, 1989).

Por último, queremos destacar la significativa ubicación de Torremorana, cerca del limite que divide en dos ámbitos culturales la zona Andaluza, el turdetano y el bastetano (PEREIRA, 1989; RUIZ RODRIGUEZ, 1992; CHAPA, PEREIRA, 1993) ${ }^{19}$. Sin pretender entrar de lleno en un tema tan escurridizo como es el de los indicadores étnicos, áreas etno-culturales, etc. en Andalucía, por su extrema complejidad ${ }^{20}$, sí queremos insistir en la situación de Torremorana, aguas abajo en la cuenca del Guadajoz, y relativamente próximo a la necrópolis de Almedinilla, que se ha adscrito culturalmente al grupo bastetano (VAQUERIZO, 1993), máxime cuando buena parte del material estudiado encuentra los paralelos mas cercanos en las necrópolis de Los Collados y algunos menos en Los Torviscales como hemos referido mas arriba (ver figura 2). No obstante su incursión en un área u otra rebasa los límites de este trabajo máxime teniendo en cuenta sólo el aspecto armamentístico, elemento que per se se presta poco a esta labor (QUESADA, 1989: 119). Sólo con un adecuado proyecto de investigación pluridisciplinar que incluyera la excavación y se abordasen los rasgos definitorios de las comunidades étnicas, culturales y políticas de la Andalucía Prerromana se podría, quizás, clarificar este tema.

18 En este sentido nos adherimos a las propuestas de F. Quesada (QUESADA, 1999), considerando que los materiales estudiados, aunque en algunos casos hayan sido considerados como de origen meseteño, vienen perteneciendo claramente al ámbito cultural ibérico, como demuestra la dispersión y cronología de los hallazgos.

19 ChAPA, PEREIRA, 1993: 95 llevan una de las manifestaciones del supuesto ámbito bastetano, las representaciones de cérvidos, hasta Baena.

20 Una reciente síntesis sobre el tema en ESCACENA, 2000. 
MANUEL SIERRA MONTESINOS

Avda. de Cádiz, Ed. «Los Jardines 1»14013 Córdoba

\section{BIBLIOGRAFÍA}

Adroher Auroux, A. M., López Marcos, A. (1992): «Estudio de cerámicas de barniz negro en los Museos Arqueológicos de Granada y Jaén». Anuario Arqueológico de Andalucía 1990. Actividades sistemáticas. 307-309.

AlmAGRo-GorbeA, M. (1987): «El área superficial de las poblaciones ibéricas». Los asentamientos ibéricos ante la romanización. Madrid. 21-34.

Arribas, A.; Trias, G.; Cerda, D.; DE Hoz, J. (1987): El barco de El Sec (Galviá, Mallorca). Palma de Mallorca.

BERNIER, J et alii (1981): Nuevos yacimientos arqueológicos en Córdoba y Jaén. Córdoba.

CABRe HerReros, M. E. (1934a): «El modelo de falcata más típicamente hispánico». ANABA II. 207-212.

Cabre Herreros, M. E. (1934b): «Dos tipos genéricos de falcata hispánica». A. Esp. A. X. 207-224.

CABRE DE Morán, M. E. (1990): «Espadas y puñales de las necrópolis celtibéricas». II Simposio sobre los Celtíberos. Necrópolis celtibéricas. 205-224. Zaragoza.

CABRE, M. E., BAQUEDANO, I. (1991): «La guerra y el armamento».Revista de Arquelogía. Número monográfico «Los Celtas». 58-71.

ChAPA, T., Pereira, J. (1993): «Las etnias prerromanas del Sureste: problemas de su comprobación arqueológica». Actas del II Congreso de Historia Antigua de Andalucía, t. III. Córdoba. 89-105.

CuAdRAdo DíAz, E. (1963): «La cerámica ática de barniz negro de la necrópolis de El Cigarralejo (Mula, Murcia)». A.P.L. X. 97-164.

CuAdRAdo DíAz, E. (1987): La necrópolis ibérica de El Cigarralejo (Mula, Murcia).B.P.H. XXIII. Madrid.

CuAdrado DíAz, E. (1989): La panoplia ibérica de El Cigarralejo (Mula, Murcia). Documentos. Serie Arqueología 1. Murcia.

EsCACENA CARRASCO, J. L. (2000): La arqueología protohistórica del sur de la Península Ibérica. Madrid.

ForteA, J., Bernier, J. (1970): Recintos y fortificaciones ibéricos en la Bética. Memorias del Seminario de Prehistoria y Arqueología. Salamanca.

Hernandez, L., SAlA, F. (2000): «Una punta de lanza decorada de la necrópolis de El Puntal (Salinas, Alicante)». Gladius 20. 179-190.

MALUQUeR DE Motes, J. (1973): «La necrópolis ibérica arcaica de La Bobadilla (Jaén)». P.I.P. Univ. de Barcelona 1. Barcelona.

MARCOS, A., VicenT, A. M. a (1983): «La necrópolis ibero-turdetana de Los Torviscales, Fuente Tójar». Novedades de Arqueología Cordobesa. Exposición Bellas Artes 1983. Córdoba.

MELCHOR GIL, E. (1995): Las vías romanas de la provincia de Córdoba. Córdoba.

Miro, J. H. ReIG, C. (1997): «Los cubos de enmangue de lanzas y regatones ibéricos. Análisis y diagnóstico». Recerques del Museu d'Alcoi, 6. 161-164.

MORET, P. (1996): Les fortifications ibériques. De la fin de l'Age du Bronze à la conquête romaine. Madrid. 
MURILlo et alii, (1989): «Aproximación al estudio del poblamiento protohistórico en el sureste de Córdoba: unidades políticas, control del territorio y fronteras». Fronteras. Arqueología Espacial 13. Teruel. 151-172.

Pereira Sieso, J. (1988): «La cerámica ibérica en la Cuenca del Guadalquivir II. Conclusiones. A. Esp. A. 46. 149-159.

PÉREZ, F., QueSADA, F. (2001): «Una nueva espada de antenas atrofiadas en el Museo Histórico Local de Villa del Río (Córdoba). «Antiqvitas 13. Priego de Córdoba. 105-116.

QuESADA SANZ, F. (1989): «Consideraciones sobre el uso del armamento ibérico para la delimitación de unidades geopolíticas» Arqueología Espacial 13.Fronteras, Teruel, pp. 111-120.

Quesada SAnZ, F. (1992): «Notas sobre el armamento ibérico de Almedinilla». A.A.C. 3. Univ. de Córdoba. 113-135.

QUESADA SANZ, F. (1992): La falcata ibérica: arma y símbolo. Alicante.

QUESADA SANZ, F. (1997):, El armamento ibérico. Estudio tipológico, geográfico, funcional, social y simbólico de las armas en la Cultura Ibérica (siglos VI-I a.C.). Monographies Instrumentum 3. Montaignac.

QuESADA SANZ, F. (1999): «Porcuna, Cástulo y la cuestión del supuesto carácter meseteño, indoeuropeo o céltico de su panoplia: el ‘armamento ibérico' como armamento ibérico». R. Balbín y P. Bueno (eds.) II Congreso de Arqueología Peninsular. Zamora. Vol. III. 425-434.

Quesada Sanz, F. (2000): Recensión de J. Alonso, R. Cerdán, I. Filloy, Nuevas técnicas metalúrgicas en armas de la II Edad del Hierro. Gladius 20.313-317.

QuESADA SANZ, F. (2001): «Rellenando los mapas: nuevos conjuntos funerarios ibéricos con armas en la provincia de Córdoba». Antiqvitas 13.73-103.

REIG SEGUI, C. (2000): «El armamento de la necrópolis ibérica de La Serreta de Alcoi(Alicante, España)». Gladius 20. 75-117.

Ruiz RodrígueZ, A. (1992): «Etnogénesis de las poblaciones prerromanas de Andalucía Oriental».M. Almagro-GorbeA, G. Ruiz-Zapatero (Eds.) Paleoetnología de la Península Ibérica. Complutum, 2-3. 101-118.

RuIZ, A. MolinOs, M. (1993): Los iberos. Análisis arqueológico de un proceso histórico. Barcelona.

SCHÜLE,W. (1969): Die Meseta-Kulturen der Iberischen Halbinsel. 2 vols. Berlin.

SIERRA MONTESINOS, M. (2001): «Espada tipo Alcacer-do-Sal de una colección particular». Antiqvitas 13.115-121.

SIERRA, M., PÉREZ, F. (e.p.): «Nuevas aportaciones al estudio del armamento ibérico en la provincia de Córdoba».

VAQUERIZO GIL, D. (1989): «Armas de hierro procedentes de la necrópolis ibérica de 'Los Collados’ (Almedinilla, Córdoba)». Saguntum. PLAV 22. 225-266.

VAQUERIZO GIL, D. (1993): «Las necrópolis ibéricas de Almedinilla (Córdoba): su interpretación en el marco socio-cultural de la antigua Bastetania». Actas del I Coloquio de Historia Antigua de Andalucía. Córdoba. Vol. I. 247-289.

VAQuerizo GIL, D. (1999): La Cultura Ibérica en Córdoba. Un ensayo de síntesis. Córdoba.

VAQUERIZO, D.; QUESADA, F.; MURILlO, J. F. (2001): Protohistoria y Romanización en la Subbética cordobesa. Una aproximación al desarrollo de la Cultura Ibérica en el sur de la actual provincia de Córdoba. Sevilla.

VICENT, A. Ma (1984-85): «Trabajos arqueológicos inéditos en Fuente Tójar (Córdoba) de L. Maraver en 1867». Corduba Archaeológica 15, 31-54. Córdoba. 